
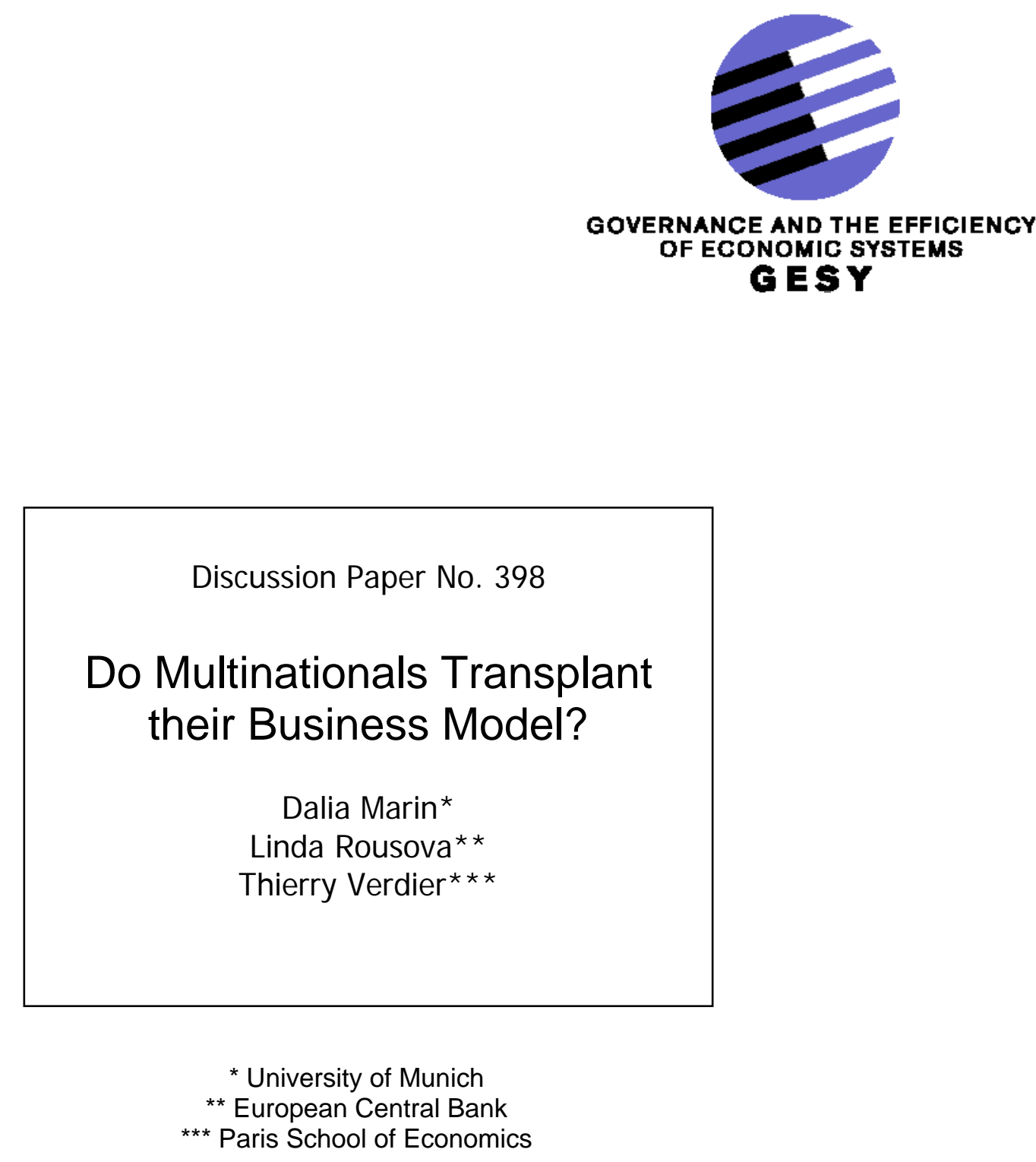

April 2013

Financial support from the Deutsche Forschungsgemeinschaft through SFB/TR 15 is gratefully acknowledged. 


\title{
Do Multinationals Transplant their Business Model?§
}

\author{
Dalia Marin*, Linda Rousova**, Thierry Verdier***
}

April 2013

\begin{abstract}
What determines whether or not multinational firms transplant their mode of organisation to other countries? We embed the theory of knowledge hierarchies in an industry equilibrium model of monopolistic competition to examine how the economic environment may affect the decision of a multinational firm about transplanting its business organisation to other countries. We test the theory with original and matched parent and affiliate data on the internal organisation of 660 Austrian and German multinational firms and 2200 of their affiliate firms in Eastern Europe. We find that three factors stand out in promoting the multinational firm's decision to transplant the business model to the affiliate firm in the host country: a competitive host market, the corporate culture of the multinational firm, and when an innovative technology is transferred to the host country. These factors increase the respective probabilities of organisational transfer by 18.5 percentage points, 37 , and 31 percentage points.
\end{abstract}

Keywords: organisational economics of multinational firms, trade and organisations, the theory of the firm, organisational transfer between countries

JEL Codes: D23 F12 F23 F61

$\S$ Marin would like to thank the Harvard University Department of Economics, where some of this paper was written, for its hospitality. We would like to thank participants at the European Research Workshop in International Trade, Rotterdam 2013, the American Economic Association Meeting, San Diego 2013, the European Economic Association Meeting, Málaga 2012, the Italian Trade Study Group Meeting, Trento, the European Bank for Reconstruction and Development and Paola Conconi for helpful comments and Jan Schymik for excellent research assistance. We also gratefully acknowledge financial support from the Deutsche Forschungsgemeinschaft through SFB/TR 15 and the European Commission under the FP7 Framework programme "SCience, Innovation, FIrms and Markets in a Globalised World (SCI-FI GLOW)". The views expressed in this paper are those of the authors and do not necessarily reflect those of the ECB.

*University of Munich, dalia.marin@lmu.de, ** European Central Bank, linda.rousova@ecb.int, *** Paris School of Economics, thierry.verdier@ens.fr 


\section{Introduction}

When multinational firms invest abroad, they surprisingly often do not operate with the same organisational form as their parent firms in the home country. Table 1 documents for the first time that in about 50 percent of foreign investments, multinational firms do not transplant their parent firms' mode of organisation to the affiliate firm in the host country. The numbers shown in Table 1 are based on survey data we designed and collected on the internal organisation of 660 Austrian and German multinational firms with 2200 of their affiliates in Eastern Europe (for more details on the survey and the data, see Section 6.1 and Marin and Rousova (2012)). We collected information on the hierarchical level of 13 corporate decisions in affiliate and parent firms, such as decisions on acquisitions, finance, budget, R\&D, new strategy, firing of personnel, etc. (see Table 5 of the Data Appendix B for a full listing of corporate decisions). The measure of organisational transfer we use is based on the number of corporate decisions which are taken at the same hierarchical level in affiliate firms as in parent firms. The organisational form is fully transplanted if each corporate decision obtained the same hierarchical rank in the affiliate firm as in the parent firm; it is partially transplanted if from two to four corporate decisions differ, and it is not transplanted if more than five corporate decisions differ in hierarchical rank in the parent and affiliate firms (see Figure 4 of Appendix $\mathrm{B}$ for the frequency of transplanting individual corporate decisions). 1

Why are business organisations so little transplanted? Why do the same firms use different organisations in different markets? Most of the literature on multinational firms assumes that multinational firms bring technology and organisational skills to the host countries. In a recent paper, Bloom, Van Reenen, and Sadun (2012) suggest that multinational firms are more decentralised than domestic firms because they take with them the more decentralised organisation from their parent firms when they invest in other countries. But the data on the frequency of exporting the organisational form to host countries documented in Table 1 does not suggest that organisational transfer can be taken for granted. The recent literature on international trade shows that multinational firms tend to be larger and more productive than firms that serve only the national market (see Helpman, Melitz, and Yeaple (2004)). The larger firm size of multinational corporations may itself explain why they operate with a more decentralised organisation compared to national firms. In fact, two recent papers on

\footnotetext{
${ }^{1}$ Alternatively, we consider several measures of transplanting the mode of organisation with similar results. See Table 8 of Appendix B.
} 
trade and organisation based on different theories of firm hierarchies (see Marin and Verdier (2010); Caliendo and Rossi-Hansberg (2012)) predict that larger firms more exposed to international trade are more decentralised. What then determines whether or not multinational firms transplant their mode of organisation to other countries?

Table 1: Do Multinationals Transplant their Business Model?

\begin{tabular}{ccccc}
\hline \multirow{2}{*}{ Parent Firm in: } & \multicolumn{2}{c}{ Affiliate Firms } & with Parent Firm \\
& & Transplanted: & Organisation & Total \\
& Not $^{1}$ & Partially $^{1}$ & Fully $^{1}$ & Affiliate Firms \\
\hline \multirow{2}{*}{ Austria } & 462 & 242 & 178 & 882 \\
& $52.4 \%$ & $27.4 \%$ & $20.2 \%$ & $100 \%$ \\
Germany & 200 & 113 & 144 & 453 \\
\hline \multirow{2}{*}{ Total Affiliate Firms } & $44.2 \%$ & $24.9 \%$ & $30.9 \%$ & $100 \%$ \\
& 662 & 355 & 318 & 1335 \\
\hline
\end{tabular}

Notes: The table reports the absolute number of cases and row percentages. at the same hierarchical level in the parent and subsidiary firms. For a listing of corporate decisions, see Table 5 in Appendix B The organisational form is fully transplanted if each corporate decision obtained the same hierarchical rank for the subsidiary firm as for the parent firm, or if only one corporate decision differs. It is partially transplanted if two to four corporate decisions differ in hierarchical rank, and the organisational form is not transplanted if five or more corporate decisions are different.

In this paper, we focus on the role of the economic environment in the decision to export the organisational form to other countries. If 'corporate culture' matters, we a priori expect firms to operate with the same organisational form in the countries they invest in. Presumably, once the firm has developed an organisational routine which serves it well, it might as well use this routine in other countries. One possible reason why this often does not happen is that the economic environment may force firms to adjust their organisational form to the conditions prevailing in these markets.

To get a first impression on whether the economic environment matters for the frequency of exporting the business organisation, we look in Table 1 at whether the size of the home market of multinational firms is correlated with the decision to transplant their mode of organisation. This is indeed the case. German multinationals, located in the larger economy, transplant their organisational form significantly more often than Austrian multinationals, located in the smaller home market.2 Furthermore, in Figure 1 we show that the market size of the host countries in Eastern Europe is correlated with the frequency with which the parent multinational firm, whether from Austria or Germany, brings the organisational form with them when they invest in these countries. The figure ranks the host countries by their size in terms of GDP (with Bosnia the

\footnotetext{
${ }^{2}$ Austria has a population of 8 million people, which is 10 percent of that of Germany.
} 
smallest and Russia the largest) and suggests that multinational firms appear to transplant their organisational form more often to smaller host markets. Equipped with this information, we proceed in this paper with a theory in which multinational firms' decisions to transplant their organisational form will be described as a function of the monopolistic competitive environment they face in the home market and in the host market. We then test this theory with the survey data of 660 multinational firms and their 2200 affiliate firms in Eastern Europe.

Figure 1: Host Country Size and the Decision to Transplant the Organisational Form

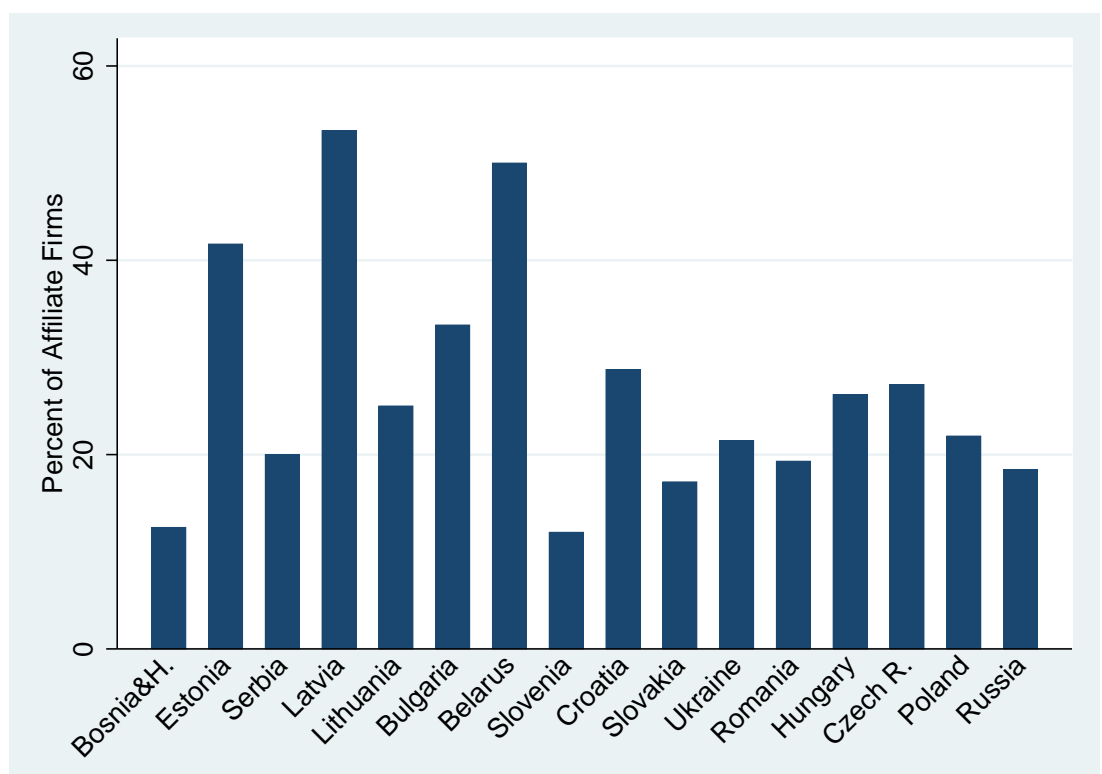

Notes: The figure shows the percentage of affiliate firms in a given host country with parent firm organisational form fully transplanted. Host countries are sorted by the size of GDP from left (smallest GDP) to right (largest GDP). Countries with less than 8 affiliate firms are not shown.

We model an economy in which a multinational firm decides how to organise production in the parent and the affiliate firm in a host country. We follow a variant of Garicano (2000) and Garicano and Rossi-Hansberg (2006) and model the organisation of the multinational firm as a knowledge-based hierarchy in which the production managers in the parent and affiliate firms deal with routine problems and headquarters (top managers) solve the exceptional problems. Production managers need to acquire knowledge to solve problems, which is costly. Therefore, it is efficient for the firm to let the top managers learn how to solve the more uncommon problems. In addition to solving the problems that the production managers cannot solve, the top managers 
coordinate the projects of the production managers. The coordination costs of the top managers introduce a size cost to the firm hierarchy. The more problems have to be solved, the larger is the scale of production, the more time is spent on coordination, and the less time is available for problem solving. The problem of the firm is to decide on the size of the hierarchy, the level of decentralisation to production managers, and the optimal scale of production. A more decentralised organisation of production allows the firm to save on top managerial wages and communication costs at the expense of larger training costs for the production managers. We show that, depending on which of these costs dominate, the optimal scale of production at first rises and then falls with increasing autonomy of production managers.

We incorporate our multinational firm in a home market with monopolistic competition with a continuum of differentiated goods. Consumers in the home market have a linear demand for varieties. Hence, firms determine prices by choosing the size of the markup endogenously. We then consider how changes in the economic environment (changes in product markets) affect the output and the level of decentralisation in our multinational firm. We find that an increase in market size leads to a larger output level of firms and to more decentralisation (i.e., delegation of decision-making to production managers), while an increase in the number of competitors leads to lower ouput and less decentralisation. When the market and the firms' scale of production become larger, the top managers are required to coordinate more, which increases the opportunity costs of their solving problems. As a result, headquarters increases the fraction of tasks that the production managers have to solve, leading to more delegation and decentralisation. When competition becomes more intense and firms' output declines, less coordination and more supervision is called for, resulting in more centralisation.

Next, we allow our multinational firm to sell its product in a host country through an affiliate firm which faces monopolistic competition in the host market. We then examine the conditions under which the multinational firm will use the same organisational form in the affiliate firm in the host country as in the parent firm in the home country. The first result of the paper states that the market environment exhibits a powerful influence on the multinational firms' decision to transplant their business organisation to the affiliate firm in the host country. Interestingly, we find that multinational firms coming from smaller home markets and investing in larger host markets are less likely to export their form of business organisation to the affiliate firm in the host country. In a smaller home market, the multinational firm adopts a more centralised hierarchy, since a smaller ouput allows for more supervision and less coordination by headquarters. 
Assuming that affiliate firms are more decentralised than parent firms (which we show will prevail when communication costs between parent and affiliate firms are sufficiently large), more centralisation in the parent multinational firm increases the organisational gap with the affiliate firm, making it less likely that the organisational form is transplanted. In a larger host market, it hurts the profits of the affiliate firms more when they operate with an organisational form that is not optimally adjusted to the host market conditions. When affiliate firms operate with the same organisational form as their parent firms in their host markets, each unit of output is sold with a lower profit margin, reducing total profits when more units of output are sold in the larger host market.

We find further that multinational firms coming from less competitive home markets and investing in more competitive host markets are more likely to export their form of business organisation to the affiliate firms in the host country. In a less competitive home market, the multinational firm adopts a more decentralised hierarchy, since a larger ouput allows for less supervision and more coordination by headquarters. More decentralisation in the parent multinational firm decreases the organisational gap with the affiliate firm, making it more likely that the organisational form is transplanted. Similarly, more competition in the host market means that the optimal size of the affiliate firm shrinks and headquarters allocates less time to coordination and more to supervision resulting in more centralisation. This decreases the organisational gap with the parent firm, making it more likely that the organisational form is transplanted.

The second result of the paper states that gravity factors like distance and communication costs between parent firms and their affiliates affect the probability of organisational transfer to the host country. An increase in communication costs has an ambiguous effect on the probability of transplanting the mode of organisation. On the one hand, more costly communication leads to more decentralisation in the affiliate firm increasing the organisational gap to the parent firm, and hence lowers the probability of transplanting the mode of organisation. On the other hand, more costly communication increases marginal costs of production and reduces profits. The profit loss is smaller when the firm transplants the organisational mode which increases the probability of organisational transfer. We show that the first effect dominates the second effect and, hence organisational transfer is less likely when the home market is sufficiently large.

Finally, the last result of the paper states that multinational firms with stronger 
corporate culture and more innovative technologies are more likely to transplant the mode of organisation to the host country. A stronger corporate culture makes a change of organisation more costly increasing the probability of transplanting the mode of organisation. When a more innovative technology is transferred to the affiliate firm, the training costs of production managers in the affiliate firm rise, and hence the affiliate firm recentralizes to headquarters with a smaller organisational gap to the parent firm resulting in an increase in the probability of transplanting the organisational mode. Thus, organisational transfer and technology transfer appear to be complements.

We test the predictions of our theory with original firm survey data we collected and designed from 660 Austrian and German multinational parent firms with their 2200 affiliate firms in Eastern Europe. In the empirical analysis we test for the probability of transplanting the organisational form and we show that the estimated coefficients have mostly the predicted sign and are highly significant at conventional levels. The market environment variables and gravity factors are economically important for the probability of organisational transfer to host countries. For example, we find that when the population ratio of the host to the home country as a measure of relative market size increases by 1 , the probability of transplanting declines by 2 percentage points. In our data this means that if a German multinational firm moves its affiliate firm from the smaller Ukraine to the larger Russia, the probability of transplanting their organisational form declines by 2.4 percentage points. When affiliate firms face many domestic competitors in their host markets rather than a few, the probability of transplanting increases by 18.5 percentage points, while many domestic competitors in the home market of multinational parent firms lower this probability by around 9 percentage points. When the distance between the parent and affiliate firm doubles the probability of transplanting the organisational mode declines by 8 percentage points.

Moreover, the corporate culture of the multinational firm and the type of technology transferred to the host country matter for the decision to transplant the mode of organisation. Multinational firms with human resource policies in place (our measure of corporate culture) are 37 percentage points more likely, and multinational firms which transfer an innovative technology to the affiliate firm are 31 percentage points, respectively, more likely to transfer the organisational mode to the host country. 
While there is a large economic literature which has examined the determinants of technology transfer between countries (for a recent survey, see Harrison and RodriguezClare (2010) ), research on organisational transfer between countries virtually does not exist. However, there is a large empirical literature in international business which emphasizes the tension between the adjustment to local market conditions and the transfer of intangible assets, of the mode of organisation, and human resource management practices in multinational firms, see for example Florida and Kenney (1991), Ferner et al. (2004). Moreover, the literature on the transplantation of culture between countries which follows the epidemiological approach (see Fernandez (2011)) is related to what we do in this paper. The epidemiological approach tries to separate the effect of culture from the economic and institutional environment by studying variations in outcomes across groups with different cultural backgrounds (immigrants, diplomats) residing in the same country (see Fernandez and Fogli (2009), and Fisman and Miguel (2007)). We instead want to understand the role of the economic environment in corporate outcomes in firms that share the same corporate culture, by coming from the same multinational parent firms but differing in the economic enviroments faced by their affiliated firms in their differing host countries.

Our paper is also related to previous research on organisations in international trade ${ }^{3}$ Helpman, Melitz, and Yeaple (2004) and Antras and Helpman (2004) focus on how firms' home productivity advantage determines the mode of organisation firms choose abroad. Antras, Garicano, and Rossi-Hansberg (2006) study the formation of teams between countries, and Marin and Verdier (2008, 2010, 2012) and Caliendo and Rossi-Hansberg (2012) examine how a greater exposure to international trade influences the business model firms choose at home. More recently, an empirical literature on firm decentralisation has emerged with a focus on national firms. This literature examines the trend to decentralisation of US firms (Rajan and Wulf (2006)), how information technology (Bloom, Van Reenen, and Sadun (2012); Acemoglu et al. (2007)), international trade and competition (Marin and Verdier (2010); Guadalupe and Wulf (2010); Caliendo, Monte, and Rossi-Hansberg (2012)) and trust and religion (Bloom, Van Reenen, and Sadun (2010) ) affect the level of decentralisation of firms.

The present paper is organised into the following sections. Section 2 describes the product market with monopolisitc competition. Section 3 introduces the organisational form of the firm as a knowledge hierarchy and derives the optimal scale of production

\footnotetext{
${ }^{3}$ For an overview, see Helpman, Marin, and Verdier (2008) and Marin (2012).
} 
and the optimal level of decentralisation in the firm. Section 4 embeds the optimal choice of knowledge hierarchy in a one sector economy with monopolistic competition and examines how the conditions in the product market influence the optimal choice of the knowledge hierarchy. Section 5 extends the analysis to examine the choice of a multinational firm operating both in the home market as well as in a host market through a subsidiary firm. This section derives the conditions under which the multinational firm will transplant their organisational form to the affiliated firm in the host market. Section 6 describes the data and the empirical results and Section 7 concludes. The proofs of the main results and the description of the data are relegated to the Appendix.

\section{Product Market}

Consider an economy with $L$ consumers whose preferences are defined over a continuum of differentiated varieties indexed by $i \in \Omega$ and a homogenous good chosen as the numd'ż"raire. Preferences are given by

$$
U=q_{0}+\int_{i \in \Omega} q_{i} d i-\frac{1}{2} \gamma \int_{i \in \Omega} q_{i}^{2} d i-\frac{1}{2}\left[\int_{i \in \Omega} q_{i} d i\right]^{2},
$$

where $q_{0}$ and $q_{i}$ are, respectively, the consumptions of the numeraire and of variety $i$ of the differentiated good.

Assuming that there are $N$ varieties on the market, utility maximisation for a typical consumer provides demand for each variety $i$

$$
d_{i}\left(p_{i}, \bar{p}\right)=\frac{1}{\gamma+N}-\frac{1}{\gamma} p_{i}+\frac{N}{\gamma+N} \frac{1}{\gamma} \bar{p}
$$

where $d_{i}\left(p_{i}, \bar{p}\right)$ is the market demand for variety $i, \gamma$ is the degree of product differentiation between varieties $i, p_{i}$ is the price of variety $i$, and $\bar{p}=\frac{1}{N} \int_{i \in \Omega} p_{i} d i$ is the average price index $\bar{p}$ in the differentiated good sector. The aggregate demand for variety $i$ is simply $q_{i}\left(p_{i}, \bar{p}\right)=L d_{i}\left(p_{i}, \bar{p}\right)$. Note that in this linear demand system for varieties, the price elasticity of demand is driven by the toughness of the competition in the market induced either by a lower average price for varieties $\bar{p}$ or more product 
varieties $N$. The price elasticity of demand increases with lower $\bar{p}$ and larger $N{ }^{4}$

Each variety of the differentiated good is produced under monopolistically competitive conditions. Our focus is on one specific firm $i$ operating in this market and selling a given variety $i$. We think of this firm as reflecting the headquarters or the subsidiary of a multinational firm in a specific country. We wish to characterise the residual demand for that specific firm when it competes with $N$ other local firms $j \neq i$ (each of them selling one variety of the differentiated product on that same market). Suppose that all the other firms produce with constant marginal costs $c$. Then the profit maximisation of each of these firms is given by

$$
\max _{p_{j}} \pi_{j}\left(p_{j}\right)=L d_{j}\left(p_{j}, \bar{p}\right)\left[p_{j}-c\right]
$$

with profit maximising output level $q_{j}=q(c)$ and price level $p_{j}=p(c)$, respectively, as

$$
q_{j}=q(c)=\frac{L}{\gamma}\left[p_{j}-c\right]
$$

with

$$
p_{j}=p(c)=\frac{1}{2}\left[c+\frac{\gamma}{\gamma+N}+\frac{N}{\gamma+N} \bar{p}\right] .
$$

Averaging over all the local competitors' results in the average price on the market (when there are enough varieties $N$ ) as

$$
\bar{p}=\frac{1}{N} \int_{j \in \Omega} p_{j} d j=p(c)=\frac{1}{2}\left[c+\frac{\gamma}{\gamma+N}+\frac{N}{\gamma+N} \bar{p}\right]
$$

or

$$
\bar{p}=\frac{c+\frac{\gamma}{\gamma+N}}{\frac{2 \gamma+N}{\gamma+N}} .
$$

Substituting into (1), the multinational firm of our focus $i$ faces an aggregate demand:

$$
q_{i}\left(p_{i}, \bar{p}\right)=\frac{L}{\gamma+N}-\frac{L}{\gamma} p_{i}+N \frac{L}{\gamma} \frac{c+\frac{\gamma}{\gamma+N}}{2 \gamma+N}
$$

\footnotetext{
${ }^{4}$ For more details, see Ottaviano, Tabuchi, and Thisse (2002).
} 
or the inverse demand function:

$$
p_{i}=P\left(q_{i}\right)=\frac{N c}{\gamma+N}+\frac{2 \gamma}{2 \gamma+N}-\frac{\gamma}{L} q_{i}
$$

and the revenue function

$$
R\left(q_{i}, L, N\right)=P\left(q_{i}\right) q_{i}=\left[\frac{N c}{\gamma+N}+\frac{2 \gamma}{2 \gamma+N}-\frac{\gamma}{L} q_{i}\right] q_{i}
$$

This formulation allows us to have a simple parametrisation of the market conditions (in terms of market size $L$ and number of competitors $N$ ) under which our firm $i$ operates.

\section{Knowledge Hierarchies}

Let us now consider the decision about the internal organisational form in our multinational firm selling its product under monopolistic market conditions. Production is described as a problem solving and information processing activity, as in Garicano (2000) and Garicano and Rossi-Hansberg (2006), who propose a simple theory of knowledge hierarchies as cognitive devices in which there is a basic trade-off between communication and information access. In their model, the role of hierarchy is to facilitate the acquisition of knowledge by increasing its utilisation rate. We use a simple version of this framework to extend the theory towards a setting with market competition, international trade, and the multinational firm.

Now consider our firm which competes on a product market as described in the previous section. To simplify, we abstract from the subscript $i$. Our firm has an inverse demand function $P(q)$ where output $q$ is produced with productive labor only.

The firm chooses the hierarchy of the organisation by taking the following considerations into account. There are two types of managers: production managers who draw a unit measure of problems (or tasks or decisions) in $[0,1]$ per unit of time, and headquarters managers who coordinate the production projects of the middle managers and also help solve production problems that middle managers are unable to solve. Production takes place only if all problems are dealt with by someone in the 
organisation and are coordinated at the level of the firm. We normalise to 1 the output per production manager and per unit of time once problems are solved. The problems are distributed according to a density function $f(z)$. Without loss of generality, the problems are ordered such that $f^{\prime}(z)<0$, i.e., more common problems have a lower index. Agents can only deal with a problem or task if they have the relevant knowledge.

The training cost of a production manager's acquiring the knowledge to deal with all problems with complexity less than $z$ is $a_{p} z$. This cost may depend on the technology available to different agents, their skill, and local market conditions in the country where the agent is. The cost of training an agent depends therefore on his autonomy $z$ (the level of complexity of problems that he can solve). When that autonomy is reduced, so that the production manager has only the knowledge for dealing with the most common problems, i.e., those in $\left(0, z_{p}\right)$, he asks for help for the more complex problems (those with $z>z_{p}$ ) from top management $m$ who may solve the problem. We assume that top managers (headquarters) have the necessary skills to be able to solve problems for all tasks in $[0,1]^{5}$.

The value of an additional layer of problem solvers is to reduce the cost of training workers to higher autonomy levels. It involves, however, several costs. First, the cost of hierarchy is the time wasted, since problem solvers do not produce output, but instead use their time to help middle managers solve their problems. Second, top managers have also to spend time coordinating projects to get effective production. The more problems have to be solved, the larger the scale of production, the more time is spent on coordination. These coordination costs of headquarters managers introduce a size cost for corporate hierarchies.

Suppose then that the organisation must deal with $q$ problems per unit of time. The team needs then $q$ production managers in layer 0 and $M$ top managers (problem solvers and coordinators) at headquarters. The profits generated by this hierarchy with $N_{p}$ production managers, each receiving a wage $w_{p}$, and $M$ top managers specialised in 'problem solving' and coordination, receiving a wage $w_{m}$ is

$$
\pi=P(q) q-\left(w_{p}+a_{p} z_{p}\right) q-w_{m} M .
$$

When the $N_{p}$ production managers have autonomy $z_{p}$ they must learn the $z_{p}$ most common problems. It is also assumed that the learning technology is such that

\footnotetext{
${ }^{5}$ In other words, $z_{m}=1$.
} 
top managers know all the tasks that the production managers also know, and that the knowledge overlaps. Whenever the production managers confront problems or decisions for which they do not have enough information, so that they need help, a communication cost $h$ (for a helping cost) per question posed must be incurred. The communication cost is only incurred when the problem could not be solved at first and help must be sought. These communication costs depend on the specifics of the organisational form and how agents interact in the organisation. First, the geographic distance between the middle managers and the top managers matters. Second, the social distance may well be affected by the 'organisational culture' of the firm. The 'organisational culture' can be defined as the formal and informal rules which influence the cost and incentives of communication in the organisation. The formal rules may be influenced by computerised information systems, routine and standardised procedures for reporting, monitoring and auditing. The informal rules may be affected by the social organisation of the firm, such as ways to organise and coordinate meetings, face-to-face modes of interaction, and the diffusion of knowledge.

A production manager can deal with a fraction $F\left(z_{p}\right)$ of the tasks and passes on $\left(1-F\left(z_{p}\right)\right.$ to a top manager in the headquarters who spends therefore time $h\left(1-F\left(z_{p}\right)\right.$ helping each of the production managers assigned to him. Each top manager also needs to coordinate production projects with the other top managers. For simplicity, we assume that the time spent in this activity is proportional to the size of the firm and given by $\varphi N_{p}$. Each top manager is endowed with 1 unit of time. Since there are $N_{p}$ production managers, the time constraint of a particular top manager is given by

$$
\operatorname{sh}\left(1-F\left(z_{p}\right)\right)+\varphi N_{p}=1,
$$

where $s$ is the span of control, or ratio of middle managers per top manager $s=$ $N_{p} / M$. The top manager spends $s h\left(1-F\left(z_{p}\right)\right)$ time solving problems, and $\varphi N_{p}$ time coordinating. It follows that the necessary number of top managers to deal with a firm of size $N$ is simply given by

$$
M=\frac{h\left(1-F\left(z_{p}\right)\right) N_{p}}{1-\varphi N_{p}}
$$

This constraint determines a trade-off between what production managers can do and how many top managers are needed. The more knowledge is acquired by middle managers, the smaller is $s h\left(1-F\left(z_{p}\right)\right)$ and the less top managers are needed. Note also, that because of the costs of coordinating between projects, the size of top management 
increases more than proportionally with the 'size' of the organisation $q$.

The problem of the firm is to decide the size or span of the hierarchy $(s)$, the degree of worker autonomy $\left(z_{p}\right)$, and the scale of production $q$ so as to maximise profits. Substituting for $M$ in equation (4), we obtain

$$
\pi\left(q, z_{p}\right)=\left[P(q)-\left(w_{p}+a_{p} z_{p}\right)-h \frac{\left[1-F\left(z_{p}\right)\right] w_{m}}{1-\varphi q}\right] q
$$

Let us define the average cost of production $c\left(z_{p}, q\right)$ by

$$
c\left(z_{p}, q\right)=w_{p}+a_{p} z_{p}+h \frac{\left[1-F\left(z_{p}\right)\right] w_{m}}{1-\varphi q} .
$$

Therefore,

$$
\operatorname{Max}_{q, z_{p}} \pi\left(q, z_{p}\right)=\left[P(q)-c\left(z_{p}, q\right)\right] q .
$$

Putting $R(q)=P(q) q$, the first order conditions of this maximisation problem are ${ }^{6}$

$$
\begin{gathered}
R_{q}^{\prime}(q)-c\left(z_{p}, q\right)-c_{q}^{\prime}\left(z_{p}, q\right) q=0 \\
-c_{z}\left(z_{p}, q\right)=0 .
\end{gathered}
$$

The solutions of this system provide the optimal level of production $q^{*}$ and the optimal degree of decentralisation $z_{p}^{*}$. To understand the intuition behind these expressions, consider the condition (7) which characterises the optimal level of autonomy $\widetilde{z}_{p}(q)$ that minimises the average costs of production $c\left(z_{p}, q\right)$ given the scale of production $q$. We can see that

$$
c_{z}\left(z_{p}\right)=a_{p}-h f\left(z_{p}\right) \frac{w_{m}}{1-\varphi q}=0
$$

\footnotetext{
${ }^{6}$ To have a well defined maximisation problem, we assume the following global concavity conditions (i.e.: $R_{q q}^{\prime \prime}-2 c_{q}^{\prime}-c_{q q}^{\prime \prime} q<0, c_{z z}^{\prime \prime}>0$, and $\Delta=-\left[R_{q q}^{\prime \prime}-2 c_{q}^{\prime}-c_{q q}^{\prime \prime} q\right] c_{z z}^{\prime \prime}-\left[c_{z}^{\prime}+c_{z q}^{\prime \prime} q\right] c_{z q}^{\prime \prime}>0$ )
} 
or

$$
\widetilde{z}_{p}(q)=f^{-1}\left[\frac{a_{p}(1-\varphi q)}{h w_{m}}\right]
$$

As $f($.$) is a decreasing function of z, z_{p}$ is obviously increasing in the communication parameter $h$ and in the top managers' wages $w_{m}$ and decreasing in the training costs of production managers $a_{p}$. A more decentralised hierarchy (larger value of $z_{p}$ ) allows a firm to save on top managerial wages and communication costs at the expense of larger training costs for the lower level workforce. Note also that $\widetilde{z}_{p}(q)$ is increasing in the size of the firm $q$. As the size of the firm increases, it is optimal to give more autonomy to production managers to save on top managers' time to coordinate projects. Condition (17) is depicted as the upward sloping curve zz in Figure 2.

Consider next condition (6), which characterises the optimal scale of production $\widetilde{q}\left(z_{p}\right)$ for a given hierarchy $z_{p}$. Taking derivatives of equation (6) with respect to $z_{p}$, we have

$$
\frac{\partial \widetilde{q}\left(z_{p}\right)}{\partial z_{p}}=\frac{c_{z}^{\prime}+c_{z q}^{\prime \prime} q}{R_{q q}^{\prime \prime}-2 c_{q}^{\prime}-c_{q q}^{\prime \prime} q} .
$$

The denominator $R_{q q}^{\prime \prime}-2 c_{q}^{\prime}-c_{q q}^{\prime \prime} q$ is negative while the numerator can be expressed as

$$
\begin{aligned}
c_{z}^{\prime}+c_{z q}^{\prime} q & =a_{p}-h f\left(z_{p}\right) \frac{w_{m}}{1-\varphi q}-h f\left(z_{p}\right) \varphi q \frac{w_{m}}{[1-\varphi q]^{2}} \\
& =a_{p}-h f\left(z_{p}\right) \frac{w_{m}}{[1-\varphi q]^{2}} \gtreqless 0
\end{aligned}
$$

A rise in $z_{p}$ increases the training costs of production managers and lowers the time top managers spend on solving problems. The first effect increases the marginal costs of production and the second effect reduces these costs. This ambiguity on the marginal costs of production is then reflected in the optimal scale of production $\widetilde{q}\left(z_{p}\right)$. Condition (6) is depicted as the inverted U-shaped curve qq in Figure 2. At small $z_{p}$ (at sufficient centralisation), the cost savings on managers dominates the increase in training costs and more decentralisation (an increase in $z_{p}$ ) unambiguously increases output. At large $z_{p}$ (at sufficient decentralisation), the reverse is the case and more decentralisation lowers output. Note that at full decentralisation $z_{p}=1$, given that $f(1)=0$, one necessarily has $c_{z}^{\prime}+c_{z q}^{\prime} q>0$ and therefore $\partial \widetilde{q} / \partial z_{p}<0$. A small move towards more centralisation saves on the training costs of production managers, but has no effect at the margin on the problem solving time of top managers. As a result, the marginal costs of production decline and the optimal scale of production $\widetilde{q}$ increases. 
Figure 2: The optimal size and level of decentralisation of the firm

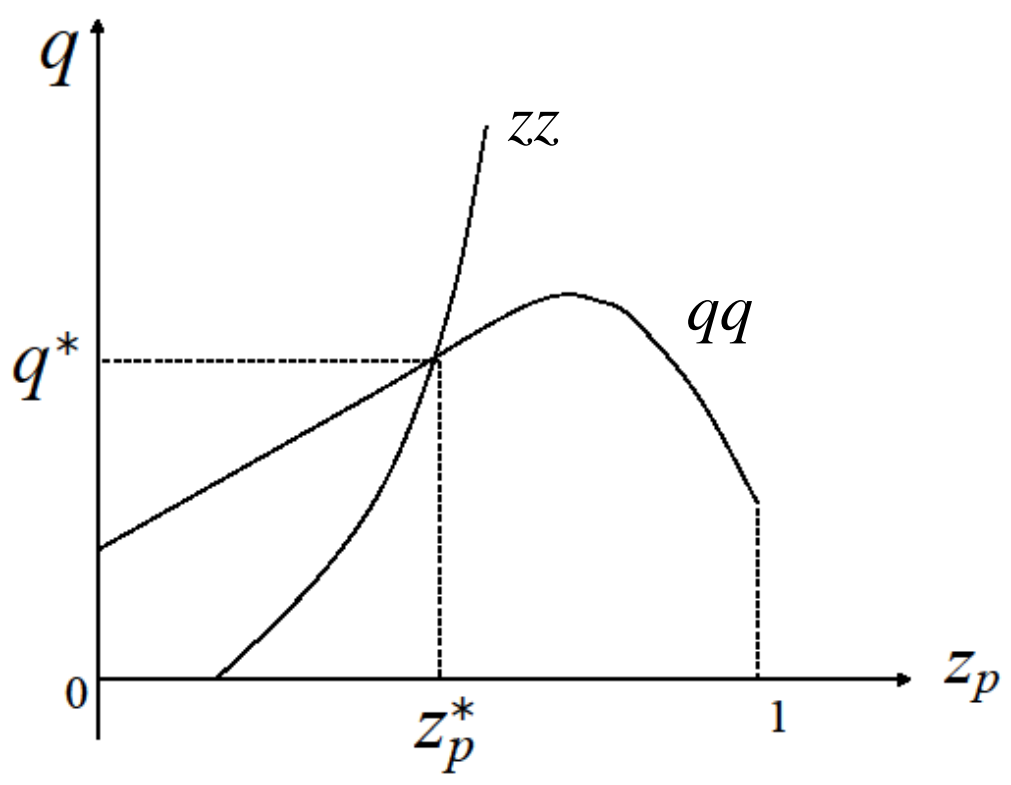

The solutions $q^{*}$ and $z_{p}^{*}$ of problem (5) are obtained when the two conditions $q=$ $\widetilde{q}\left(z_{p}\right)$ (corresponding to curve qq) and $z_{p}=\widetilde{z}_{p}(q)$ (corresponding to curve zz) are satisfied. For a well defined maximization problem of the profit function $\pi\left(q, z_{p}\right)$ (see the conditions in the Appendix), these two curves intersect as illustrated in Figure 2. Note that at the optimal level of decentralisation $z_{p}^{*}, c_{z}^{\prime}=0$. Thus, $\partial \widetilde{q}\left(z_{p}^{*}\right) / \partial z_{p}>0$ (as $\left.c_{z q}^{\prime \prime}=-h f\left(z_{p}^{*}\right) \frac{a_{m}+w_{m}}{\left[1-\varphi q^{*}\right]^{2}}<0\right)$ and the two curves (qq) and (zz) intersect on the upward sloping part of (qq).

To examine how changes in the economic environment affect the design of optimal knowledge hierarchies $z_{p}^{*}$ and the scale of production of the firm $q^{*}$, we denote by $\alpha$ and $\beta$ the shifting parameters affecting, respectively, the revenue function $R(q, \alpha)$ and the cost function $c\left(z_{p}, q, \beta\right) q$ of the firm. Typically, changes in $\alpha$ capture changes in the trade and product market environment while changes in $\beta$ capture changes in parameters affecting the internal structure of the firm. We immediately get (see Appendix A that

$$
\frac{\partial q^{*}}{\partial \alpha}=\frac{c_{z z}^{\prime \prime} R_{q \alpha}^{\prime \prime}}{\Delta} ; \frac{\partial z_{p}^{*}}{\partial \alpha}=\frac{-c_{z q}^{\prime} R_{q \alpha}^{\prime \prime}}{\Delta} .
$$

As $c_{z z}^{\prime \prime}>0, c_{z q}^{\prime}<0$ and $\Delta>0$, it follows that changes in $\alpha$ affect $q^{*}$ and $z_{p}^{*}$ in the same direction (positively when $R^{\prime \prime}{ }_{q \alpha}>0$ and negatively when $R^{\prime \prime}{ }_{q \alpha}<0$ ). 
Similarly one has

$$
\begin{aligned}
\frac{\partial q^{*}}{\partial \beta} & =\frac{-c_{z z}^{\prime \prime}\left[c_{\beta}^{\prime}+c_{q \beta}^{\prime \prime} q\right]+c_{z \beta}^{\prime \prime} c_{z q}^{\prime} q}{\Delta} \\
\frac{\partial z_{p}^{*}}{\partial \beta} & =\frac{c_{z q}^{\prime \prime}\left[c_{\beta}^{\prime}+c_{q \beta}^{\prime \prime} q\right]+c_{z \beta}^{\prime \prime}\left[R_{q q}^{\prime \prime}-2 c_{q}^{\prime}-c_{q q}^{\prime} q\right]}{\Delta}
\end{aligned}
$$

whose sign depends on the sign of $c_{\beta}^{\prime}, c_{q \beta}^{\prime \prime}$, and $c_{z \beta}^{\prime \prime}$, namely how a change in $\beta$ interacts with average and marginal costs of production, as well as the decision to decentralize.

\section{Knowledge Hierarchies and Product Markets}

In this section we analyse how conditions in the product market influence the optimal choice of the knowledge hierarchy. We examine first changes in the product markets in $q^{*}$ and $z_{p}^{*}$. As changes in the product market environment, we consider a more liberal trade regime (an increase in market size $L$ ) as well as tougher product market competition (an increase in the number of firms $N$ ).

Our firm competes in a product market as described in Section 2 with $L$ consumers, $N$ monopolistic competitors with unit cost of production $c$ and a degree of product differentiation $\gamma$. The resulting inverse demand $P(q)$ and revenue function of our firm are

$$
\begin{gathered}
P(q, \gamma, N, c, L)=\frac{2 \gamma}{2 \gamma+N}+\frac{N}{2 \gamma+N} c-\frac{\gamma}{L} q \\
R(q)=P(q) q=\left[\frac{2 \gamma}{2 \gamma+N}+\frac{N}{2 \gamma+N} c-\frac{\gamma}{L} q\right] q .
\end{gathered}
$$

We derive then the following proposition.

Proposition 4.1. i) The optimal output of the firm $q^{*}$ increases with market size $L$ and decreases with the number of competitors $N$, that is:

$$
\frac{\partial q^{*}}{\partial L}>0 \text { and } \frac{\partial q^{*}}{\partial N}<0
$$


ii) An increase in market size L leads to more decentralisation (an increase in $z_{p}^{*}$ ), while an increase in the number of competitors results in more centralisation (a decline in $z_{p}^{*}$ ), that is:

$$
\frac{\partial z_{p}^{*}}{\partial L}>0 \text { and } \frac{\partial z_{p}^{*}}{\partial N}<0
$$

Proof: See the Appendix.

Intuitively, an increase in market size leads to a larger firm output. In the Ottaviano, Tabuchi, and Thisse (2002) model we use here to describe the market structure, markups are endogenous and are declining with market size when more firms enter and compete more intensively in a larger market.7 The increase in firm size increases the coordination costs of top managers and with it the opportunity costs of solving the problems of production managers. As a consequence, it is optimal to increase the fraction of tasks $z_{p}^{*}$ that the production managers have to solve and to adopt a more decentralised hierarchy. An increase in the number of competitors reduces the firms' market shares and output. As a result, the coordination costs at headquarters decline, leading to more centralisation of tasks to the top managers (i.e., a lower value of $z_{p}^{*}$ ).

Next, we consider how changes in the cost side parameters affect $q^{*}$ and $z_{p}^{*}$ in the following proposition. As changes on the cost side, we examine changes in training costs of production managers $a_{p}$ and in costs of communication $h$.

Proposition 4.2. i) An increase in the learning costs of production managers $a_{p}$ leads to a lower optimal output and to more centralisation:

$$
\frac{\partial q^{*}}{\partial a_{p}}<0 \quad \text { and } \quad \frac{\partial z_{p}^{*}}{\partial a_{p}}<0 .
$$

ii) An increase in communication costs $h$ has an ambiguous effect on output and leads to more decentralisation:

$$
\frac{\partial q^{*}}{\partial h} \gtrless 0 \text { and } \frac{\partial z_{p}^{*}}{\partial h}>0 .
$$

Proof: See the Appendix.

Intuitively, larger training costs of production managers $a_{p}$ increases production costs and leads to a lower output. The resulting lower coordination costs enables the

\footnotetext{
${ }^{7}$ see Ottaviano, Tabuchi, and Thisse $(2002$ ) for more details.
} 
top managers to get more involved in solving the problems of the production managers resulting in more centralization to headquarters (i.e., a lower value of $z_{p}^{*}$ ). An increase in communication costs $h$ makes communicating in the firm more costly, resulting in a more decentralised organisation. However, the effect of an increase in $h$ on output levels remains ambiguous. On the one hand, an increase in costs $h$ increases production costs, reducing the optimal scale of production $q^{*}$ of the firm (direct effect). On the other hand, an increase in $h$ results in a more decentralised hierarchy $z_{p}$ which allows choosing a larger output level (indirect effect). We show in the Appendix that when the hazard rate function $f(z) / 1-F(z)$ is decreasing at the optimal level of decentralisation $z_{p}^{*}$, the direct effect on output outweighs the indirect effect on output and an increase in $h$ lowers the optimal scale of production.

\section{$5 \quad$ When Will Multinationals Transplant Their Mode of Organisation?}

So far we have examined how our multinational firm (or any other firm) will organise its knowledge hierarchy when it faces a monopolistic competitive environment in its home market. In this section, we extend our analysis to examine the choice of organisational form of a multinational firm operating both in its home market and in a foreign market through a subsidiary. We want to explore the conditions under which the multinational firm will adopt the same business model in the subsidiary as in the parent firm given that the economic environment may differ in the home and host market. To do this, we use the framework of knowledge hierarchies and market competition as developed in the previous sections.

The multinational firm is assumed to have a competitive advantage compared to its competitors in the market as its output is an imperfect substitute and is produced at lower costs. From the monopolistic competition model of Section 2 , we can derive the inverse demand function of the multinational parent firm in the home market and for its affiliate firm in the host country $f$. Assuming the home (foreign) market structure is characterised by $N$ competitors with production costs $c$ and market size $L$ (by $N^{f}$, $c^{f}$, and $L^{f}$ for the foreign market), the residual demand for the parent firm in the home market and for the subsidiary firm in the host market are given by

$$
\begin{aligned}
P(q) & =P(q, c, L, N)=\frac{2 \gamma}{2 \gamma+N}+\frac{N}{2 \gamma+N} c-\frac{\gamma}{L} q \text { and } \\
P^{f}(q) & =P\left(q, c^{f}, L^{f}, N^{f}\right)=\frac{2 \gamma}{2 \gamma+N^{f}}+\frac{N^{f}}{2 \gamma+N^{f}} c^{f}-\frac{\gamma}{L^{f}} q
\end{aligned}
$$


We assume that the parent and affiliate firm share the same headquarters in the home market and both can rely on the multinational firm's accumulated knowledge and organisational experience. Hence, the parent and affiliate firm will have the same communication costs (controlling for the geographic and cultural distance between the home and host country).

Suppose now that the parent multinational firm faces the home market parameters $w_{p}, a_{p}, a_{m}, w_{m}, L, N$. Solving a problem as described in Section 3 , the firm implements a business model with an optimal knowledge hierarchy $\left(z_{p}^{O}\right)$. Suppose further that the multinational firm considers selling its product in a foreign market $f$ through a subsidiary operating in that market. Assuming that the subsidiary will be also operating under monopolistic competition, the foreign host market conditions can be summarised by the parameters $w_{p}^{f}, a_{p}^{f}, w_{m}^{f}, L^{f}, N^{f}$ reflecting local cost and demand features. The subsidiary firm faces the same problem of knowledge hierarchy as the parent firm. In order to produce effectively, production managers need to solve problems or to transmit such problems to top level managers who have greater abilities to do so.

Two features, however, are specific to the multinational firm. First, we assume that the top management of the subsidiary firm remains located in the home country at the headquarters of the parent firm. The subsidiary firm is viewed as a division of the firm located in the host country. Hence $w_{m}^{f}=w_{m}$. Second, we assume that the costs of communication with the subsidiary firm $h^{f}$ are affected by the organisational capital of the multinational firm $h^{O}=h_{0}$ (which is an intangible asset of the firm) on the one hand, and by the distance between the affiliate firm and headquarters, on the other. We put $h^{f}=h^{O}\left(1+t^{f}\right)$, where $t^{f}>0$ reflects the fact that communication costs increase with increasing geographical and cultural distance between the home and host countries. The corporate organisation of the multinational firm is illustrated in Figure 3.

We ask now whether the multinational firm will or will not transplant its organisational form $\left(z_{p}^{O}\right)$ to the subsidiary in the host market given that there is a fixed cost of changing the organisational form of $K 8^{8}$

\footnotetext{
${ }^{8}$ The idea here is that the firm has an organisational routine of how to communicate in solving problems, a routine which involves certain costs of learning and carrying out the new routines when the organisational form is changed. $\mathrm{K}$ is supposed to reflect these costs.
} 
Figure 3: The Organisation of the Multinational Corporation

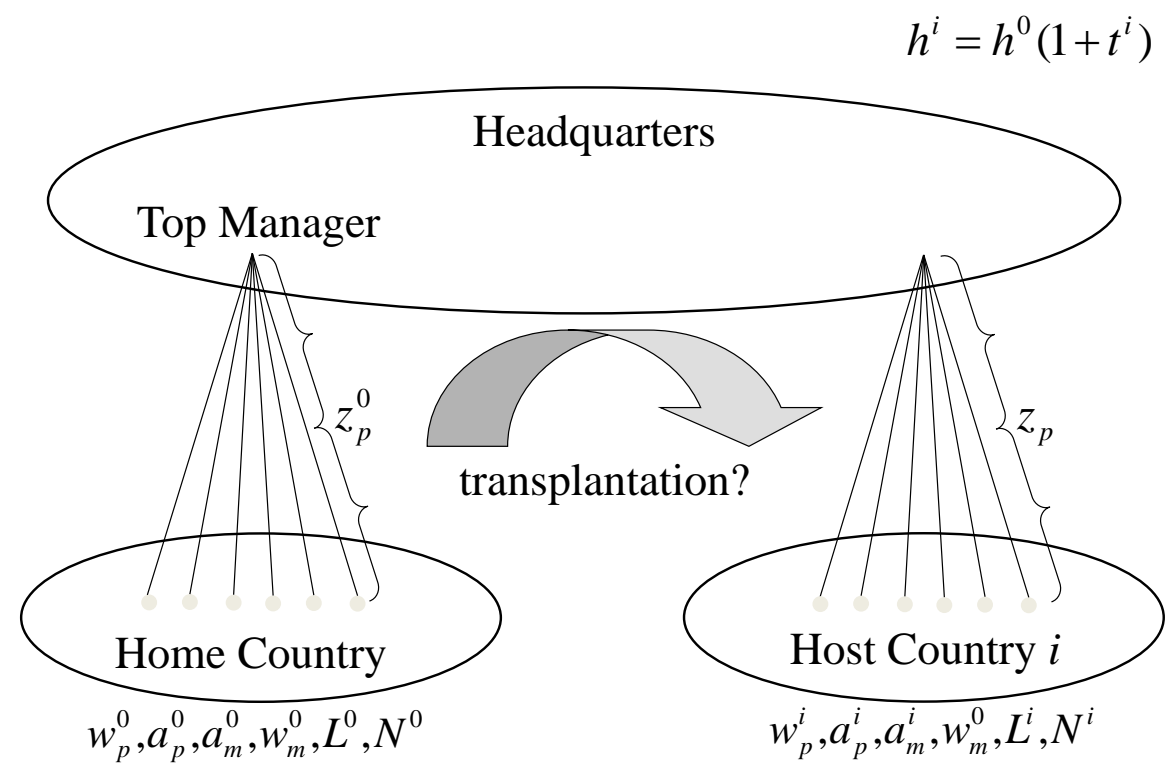

The problem can be restated as determining the conditions under which

$$
\operatorname{Max}_{q, z} \pi^{f}(q, z)-\operatorname{Max}_{q} \pi^{f}\left(q, z_{p}^{O}\right)<K
$$

holds, where

$$
\pi^{f}(q, z)=\left[P^{f}(q)-\left(w_{p}^{f}+a_{p}^{f} z\right)-h^{f} \frac{[1-F(z)] w_{m}}{1-\varphi q}\right] q .
$$

In general terms, it will be convenient to denote by $\alpha^{f}, \beta^{f}$ the shifting parameters affecting the conditions in product and factor markets in country $f$. Typically, $\alpha^{f} \in$ $\left\{c^{f}, L^{f}, N^{f}\right\}$ and $\beta^{f} \in\left\{w_{p}^{f}, a_{p}^{f}, w_{m}^{f}\right\}$.

Denote by

$$
\Pi\left(z, \alpha^{f}, \beta^{f}\right)=\operatorname{Max}_{q} \pi\left(q, z, \alpha^{f}, \beta^{f}\right)=\operatorname{Max}_{q}\left[P\left(q, \alpha^{f}\right)-c\left(z, q, \beta^{f}\right)\right] q
$$


the maximal profit function for a given hierarchy $z$, and by

$$
\widetilde{q}^{f}(z)=\operatorname{Argmax}_{q}\left[P\left(q, \alpha^{f}\right)-c\left(z, q, \beta^{f}\right)\right] q,
$$

the corresponding optimal production scale, which can be derived from the first order condition

$$
R_{q}^{\prime}\left(q, \alpha^{f}\right)-c\left(z, q, \beta^{f}\right)-c_{q}^{\prime}\left(z, q, \beta^{f}\right) q=0
$$

Denote by $\widetilde{z}_{p}^{f}(q)$ the optimal level of decentralisation that minimises the average costs of production $c\left(z, q, \beta^{f}\right)$, for a given production scale $q$, that is obtained from the following first order condition.

$$
-c_{z}\left(z_{p}, q, \beta^{f}\right)=0
$$

Solving equations (8) and (9), we derive the optimal level of production $q^{* f}$ and the optimal degree of decentralisation $z_{p}^{* f}$ in the affiliate firm facing the host market conditions $\alpha^{f}, \beta^{f}$.

The condition for transplanting the organisational form is then

$$
\operatorname{Max}_{z} \Pi\left(z, \alpha^{f}, \beta^{f}\right)-\Pi\left(z_{p}^{O}, \alpha^{f}, \beta^{f}\right)<K
$$

which requires that the increase in profit from changing the organisational form in the subsidiary firm is smaller than its costs. When this condition is met, the multinational firm replicates the parent firm's business model in the subsidiary firm.

Now consider the case when the optimal hierarchy in the subsidiary in the host country is more decentralised than that of the parent firm in the home country, that is,

$$
z_{p}^{O}<z_{p}^{* f}
$$

This condition is met when, everything else being equal, communication costs between headquarters and affiliate firms $t^{f}$ are sufficiently large $9^{9}$ When communication costs are sufficiently large, the optimal organisational form requires the subsidiary firm to

\footnotetext{
${ }^{9}$ Table 5 of the Appendix $\mathrm{B}$ shows that this assumption is indeed supported by our data as subsidiary firms are more decentralised than parent firms.
} 
save on communication costs by decentralising and letting production managers solve a wider scope of problems.

As a result,

$$
q^{* f}>\widetilde{q}^{f}\left(z_{p}^{O}\right):
$$

the optimal output of the subsidiary firm when it fully adjusts its organisational form to the host market conditions $q^{* f}$ is larger than it would be if it had transplanted the organisational form from the parent firm $\widetilde{q}^{f}\left(z_{p}^{O}\right)$.

From this follows the first result.

Result 1: A multinational firm with a more decentralised hierarchy is more likely to transplant its business model to its affilliate firm in a host country.

The prediction follows immediately from the assumption that $z_{p}^{* f}>z_{p}^{O}$, since an increase in $z_{p}^{O}$ makes 10 more likely. In other words, an increase in the level of decentralisation in the parent firm $z_{p}^{O}$ reduces the organisational gap between the parent firm's level of decentralisation and the level of decentralisation of the affiliate that is optimally adjusted to the host market conditions $z_{p}^{f^{*}}-z_{p}^{O}$. This makes it more likely that the multinational firm transplants its organisational form to its subsidiary.

\subsection{Market Size in the Home and the Host Country}

We now consider the conditions under which 10 is more or less relaxed when the parameters capturing the product market and cost conditions in the home country $\{\alpha, \beta\}$ and the host country $\left\{\alpha^{f}, \beta^{f}\right\}$ vary. Using the envelope theorem for $V\left(\alpha^{f}, \beta^{f}\right)=$ $\operatorname{Max}_{z} \Pi\left(z, \alpha^{f}, \beta^{f}\right)$, the impact of $\alpha^{f}$ on the decision to transplant is given by the sign of

$$
R_{\alpha}^{\prime}\left(q^{* f}, \alpha^{f}\right)-R_{\alpha}^{\prime}\left(\widetilde{q}^{f}\left(z_{p}^{O}\right), \alpha^{f}\right) .
$$

Given that $q^{* f}>\widetilde{q}^{f}\left(z_{p}^{O}\right)$, this will depend on the sign of $R_{\alpha q}^{\prime \prime}\left(q, \alpha^{f}\right)$. When $R_{\alpha q}^{\prime \prime}\left(q, \alpha^{f}\right)>$ $0(<0)$, an increase in $\alpha^{f}$ makes it less (more) likely that the firm transplants its organisational form to the subsidiary.

Similarly, the impact of $\beta^{f}$ on the decision to transplant is given by the sign of

$$
-c_{\beta}\left(z_{p}^{* f}, q^{* f}, \beta^{f}\right) q^{* f}+c_{\beta}\left(z_{p}^{O}, \widetilde{q}^{f}\left(z_{p}^{O}\right), \beta^{f}\right) \widetilde{q}^{f}\left(z_{p}^{O}\right)
$$


Given that $q^{* f}=\widetilde{q}^{f}\left(z_{p}^{* f}\right)$, and $z_{p}^{O}<z_{p}^{* f}$, it will depend on the sign of

$$
\left[c_{\beta}+c_{\beta q}^{\prime} q\right] \widetilde{q}^{f \prime}(z)+c_{\beta z}^{\prime \prime} \widetilde{q}^{f}(z)
$$

and

$$
\widetilde{q}^{f \prime}(z)=\frac{c_{z}^{\prime}+c_{z q}^{\prime \prime} q^{f}}{R_{q q}^{\prime \prime}-2 c_{q}^{\prime}-c_{q q}^{\prime \prime} q^{f}}
$$

When $\left[c_{\beta}+c_{\beta q}^{\prime \prime} q\right] \widetilde{q}^{f \prime}(z)+c_{\beta z}^{\prime \prime} \widetilde{q}^{f}(z)>0(<0)$, an increase in $\beta^{f}$ makes it more (less) likely that the firm transplants its organisational form to the subsidiary.

We have then the following result.

Result 2: A multinational firm is less likely to transplant its business model to an affiliate firm operating in a host country with a larger market size $L^{f}$.

Proof: See the Appendix.

In a larger host market, it hurts the profits of the subsidiary more when it operates with an organisational form that is not optimally adjusted to the host market conditions. When the subsidiary operates with the same organisational form as the parent firm in its host market, each unit of output of the subsidiary is sold with a lower profit margin, reducing total profits when more units of output are sold in a larger host market. Therefore, the gain from changing the organisational form in the subsidiary is more likely to outweight the cost and the multinational firm does not transplant its business model to its affiliates in larger host markets.

Result 3 summarises the organisational response of the multinational corporation to changes in the home market size. More specifically, we obtain:

Result 3: Assuming $z_{p}^{f^{*}}>z_{p}^{O}$, a multinational firm with a larger home market $L$ is more likely to transplant its business model to an affiliate.

Proof: See the Appendix.

As we show in Proposition 4.1, a multinational parent firm operating in a larger home market adopts a more decentralised hierarchy (i.e., larger $z_{p}^{O}$ ). This reduces the organisational gap with the affiliate firm $z_{p}^{f^{*}}-z_{p}^{O}$ making it more likely that the multinational firm transplants its organisational form to the affiliate firm. 


\subsection{Market Competition in the Home and the Host Country}

We summarize the impact of the competitive conditions in the home and host country in the following results.

Result 4: (a) A multinational firm is more likely to transplant its business model to an affiliate firm facing tougher competition in its host country (larger number of competitors $N^{f}$ in the host market). (b) A multinational firm facing a larger number of competitors in its home market is less likely to transplant its business organisation.

Proof: See the Appendix.

Intuitively, when competition intensifies in the host country, the affiliate firm loses market share and sells fewer units of output. When the affiliate firm produces less output, headquarters' managers allocate less time to coordination and have more time to supervise the projects of production managers, leading to less autonomy in the affiliate firm. The resulting more centralised hierarchy of the affiliate firm reduces the organisational gap with the parent firm $z_{p}^{f^{*}}-z_{p}^{O}$, making it more likely that the multinational will transplant its organisational form to the affiliate firm. A multinational firms facing more competitors in its home market produces lower output with more supervision and less coordination, resulting in a larger organisational gap and a lower likelihood of exporting its business organisation to the host country affiliate.

\subsection{Distance and Communication}

In Result 5 we turn to the impact of distance and communication on the decision to transplant the mode of organisation to the host country. More specifically, we obtain:

Result 5: The more costly is the communication between multinational headquarters and the affiliate firm $h^{f}$, the less likely it is that the multinational firm transplants its organisational form to the affiliate firm. This holds, however, only when the host market is sufficiently large (when the affiliate firm is sufficiently large). 
Proof: See the Appendix.

An increase in communication costs $h^{f}$ has two opposing effects on the likelihood to transplant the business organisation to the affiliate firm. First, from Proposition 4.2, a larger $h^{f}$ makes more decentralisation of the affiliate firm desirable (i.e., a larger $z_{p}^{f^{*}}$ ).

As such, this tends to increase the 'organisational gap' $z_{p}^{f^{*}}-z_{p}^{O}$ with the parent firm and thus make it less likely that the multinational firm transplants. At the same time, however, a larger $h^{f}$ increases production costs and reduces profits. Profits decline more in affiliate firms with larger output. We have already shown that the optimal output level of the affiliate firm is smaller when it transplants its organisational form than when it optimally adjusts the organisational form to the host market conditions (i.e., $\left.\widetilde{q}^{f}\left(z_{p}^{O}\right)<q^{* f}\right)$. Therefore, profits decline less under organisational transfer than under perfect organisational adjustment to the host market. This tends to increase the benefits of transplanting the organisational form. We show in the Appendix that when the size of the affiliate is sufficiently large, the 'organisational gap effect' outweighs the 'profit effect' and a larger $h^{f}$ makes it less likely that the multinational firm transplants its business model to the affiliate firm.

\subsection{Technology}

Finally, we proceed to summarize the impact of the type of technology on the decision to transplnat the mode of business organisation in the following result.

Result 6: A multinational firm transferring a more complex and innovative technology to its affiliate firm is more likely to transplant its mode of organisation to the affiliate firm. Hence, organisational transfer and technology transfer are complements.

Proof: See the Appendix.

A more complex or innovative technology increases the learning costs of problem solving $a_{p}^{f}$ by production managers in the subsidiary firm, which makes a more centralised organisation of the affiliate firm optimal (i.e., smaller $z_{p}^{f^{*}}$ ). The resulting smaller 'organisational gap' $z_{p}^{f^{*}}-z_{p}^{O}$ with the parent firm makes it more likely that the multinational firm transplants its organisational form to the affiliate firm. 


\section{Empirical Evidence}

In this section, we test the predictions of our theory against original data about 660 multinational firms in Austria and Germany with 2200 affiliate firms in Eastern Europe and the former Soviet Union. We first describe the original data we collected from a survey among 660 multinational firms with 2200 affiliate firms in Eastern Europe. We then derive the predictions from the theory we want to test. Here, we proceed in two steps. First, we examine how the decision to transplant its organisational form is influenced by the multinational's corporate culture, communication costs, and technology. Second, we analyse how a multinational firm's decision to transplant its organisational form is affected by the market size and competition in the host and home countries.

\subsection{The Data}

We conducted a survey of 660 multinational firms in Austria and Germany with 2200 of their affiliate firms in Eastern Europe including Russia and the Ukraine and other former Soviet Republics in the period 1990-2001. Due to the length of the questionnaire, we personally visited the firms in Austria and Germany, or conducted the interviews by phone. The data are a full population survey of multinational firms in Austria and Germany investing in Eastern Europe and the former Soviet Union. Since foreign investment activity in Eastern Europe started only with the fall of communism in 1990 (under central planning, foreign ownership was prohibited), we were able to obtain 80 percent of German foreign investment and 100 percent of Austrian foreign investment in Eastern Europe during this period inspite of collecting detailed data on the internal organisation of these multinational firms and their human resource policies. The firms included in the sample are global corporations with at least two subsidiaries outside of Austria, Germany, and Eastern Europe, respectively. In 1998-1999, about 90 percent of total outgoing foreign direct investment in Austria was reoriented to Eastern Europe, while in Germany, Eastern Europe accounted for only about 4 to 5 percent of total outgoing foreign investment. This explains why the sample consists of relatively more Austrian firms inspite of Austria's being much smaller than Germany in terms of population. 


\subsubsection{Measuring Organisation, Communication, and Technology}

The dataset is unique not only because of its scope but also because of the detailed information on the internal organisation of multinational firms in general and their corporate culture in particular.10 The data include matched parent and affiliate information on the internal organisation and the multinationals' human resource policies. To our knowledge, it is the only existing dataset suitable for testing our theory.

Measuring Transplantation We measure the transplantation of the parent firm's organisational form to the affiliate firm by asking the CEO at the headquarters of the corporation, regarding the organisational form of the parent firm,: "Who decides in your company about the following corporate decisions listed in Table 5 in Appendix B]. Please rank between 1 , taken at headquarters, and 5, taken at the divisional level." We also asked, regarding the organisational form of the affiliate firm, "Who decides in your company about the following decisions listed in Table 5 of the Appendix? Please rank between 1 , taken at the headquarters of the parent firm, and 5 , taken by the manager of the affiliate firm in the host country.' The 13 corporate decisions are, decisions on acquisitions, finances, new strategy, wage increase, R\&D expenditure, budget, transfer and product prices, introducing a new product, changing a supplier, hiring two and 20 new workers, respectively as well as hiring a new secretary. Responses ranged between five hierarchical ranks with 1 as a centralised decision, taken entirely at headquarters, and 5 as a decentralised decision, taken at the divisional/affiliate level (for a full listing of the corporate decisions and their hierarchical rank in the affiliate and parent firms, see Table 5 of the Appendix B].

Based on the information of the hierarchical rank of corporate decisions in the parent and affiliate firms, we constructed our measure of transplantation of the organisational form from parent firms to foreign affiliate firms. The dummy variable full transplantation indicates whether or not the organisational form of the parent firm is fully transplanted to the subsidiary. It takes the value of one if each of the 13 corporate decisions have the same hierarchical rank or if one of the decisions differs in hierarchical rank between parent and subsidiary firms. Alternatively, we use a less stringent measure of transplantation, full transplantation (broad measure), which takes

\footnotetext{
${ }^{10}$ For a detailed overview of all the variables and their descriptive statistics, see Tables 6 and 7 of the Data Appendix B.
} 
a value of one if the hierarchical rank is the same for each corporate decision with at most two exceptions. ${ }^{11}$ Table 5 of the Appendix B shows the percentages of affiliate firms in which a particular corporate decision is taken at the same hierarchical level as in the parent firm. It is interesting to note that the most centralised and the most decentralised corporate decisions appear to be transplanted most often to affiliate firms. The very centralised decision over acquisitions and the very decentralised decision on hiring a secretary are transplanted to more than 70 percent of the affiliate firms, while the decisions on finances and $\mathrm{R} \& \mathrm{D}$ are least often transplanted to the affiliate firm. Only in about half of the affiliate firms are these two decisions taken at the same hierarchical level in the affiliate as in the parent firm.

The Level of Decentralisation We use the two survey questions on the hierarchical level of corporate decisions in affiliate and parent firms to construct an overall measure of the level of decentralisation of the decision making process in both the parent and the affiliate firm. We calculate simple means from the available scores of the 13 decisions in the parent and affiliate firms and call it the decentralisation of parent firm and the decentralisation of affiliate firm, respectively. Table 5 of the Appendix B shows that the most centralised decision is the decision on acquisitions with a mean ranking of 1.34 and 1.41 for parent and subsidiary firms, respectively, followed by the decision on a new strategy (with a respective mean ranking of 1.90 and 1.88). Not surprisingly, the most decentralised decisions tend to be the decision on hiring a secretary (mean ranking of 4.15 and 4.65) and the decision on hiring two new workers, whereas the decision on $\mathrm{R} \& \mathrm{D}$ and the decision to introduce a new product tend to be taken cooperatively between headquarters and divisional/subsidiary managers in the host country (with a respective mean ranking of 2.58 and 2.80). It is interesting to note that affiliate firms tend to be more decentralised than parent firms in Germany and Austria.

\section{Other Measures of Corporate Culture}

Human Resource Policies Our survey includes further information on the corporate culture of the multinational firm. The variables incentive salary in parent firm and incentive bonus in parent firm are dummy variables that take a value of 1 if a parent firm has a human resource policy in place to incentivise its employees

\footnotetext{
${ }^{11}$ For a robustness check with alternative measures of transplantation see Table 8 of the Data Appendix B
} 
for performance through performance based wage increases and/or one-off bonuses. While bonuses are used in more than one-third of parent firms, performance based pay increases are relatively rare, being in place in only $14 \%$ of parent firms (see Tables 6 and 7 of Appendix B). We use these variables to proxy for the cost of a change in the organisational form. The idea is that firms with explicit human resource policies are likely to have a stronger corporate culture which is supposed to be more costly to change.

Communication Costs As a proxy for communication costs, we use the variable distance between parent and subsidiary firms which is defined by the geographic distance between the capitals of the countries where the parent firm and the subsidiary firm are located. Distance is supposed to capture not only the costs of face-to-face communication but also cultural differences between the parent firms and the host regions. The further away the foreign affiliate firm from the headquarters firm, the more costly is communication between them. The average distance between parent and affiliate firms is over 900 kilometres (see Tables 6 and 7 of Appendix B).

Technology and Type of FDI In our survey we also asked the parent firms to provide us with information on the nature of the technology tranferred to subsidiary firms. The dummy technology is innovative takes a value of one if the technology is new, a dummy technology is established takes a value of one if the technology is relatively established and a dummy technology is outdated refers to a fully established or even outdated technology. Alternatively, we ask parent firms to indicate the headstart they have in the technology over their competitors in terms of how difficult it is for competitors to copy the technology. Easy-to-copy technology is a dummy variable that takes a value of one if the transferred technology is easy to copy. In most cases, the transferred technology is either established $(60 \%)$ or outdated $(32 \%)$, but this does not necessarily mean that it is easy to copy. In fact, easily copied technology can only be found in about one-third of affiliate firms (see Tables 6 and 7 of Appendix B).

Furthermore, the variable no intra-firm trade is a dummy variable equal 1 when there is no intra-firm trade between the parent and subsidiary firms. It indicates that the affiliate firm is a horizontal foreign direct investment. This variable singles out cases in which the output of an affiliate firm is not used as a (specialised) input for the parent firm but is rather sold on the host market or on a third market. Interestingly, 
around two-thirds of affiliate firms in our sample are horizontal FDI in which affiliate firms do not export their products to parent firms.

Finally, the size of the multinational corporation is measured by the number of employees as the size of parent firm and the size of affiliate firm. As expected, parent firms are usually much larger than affiliate firms: the average number of employees in parent firms reaches 7000, while it is only around 350 in affiliate firms.

\subsubsection{Measuring the Size of Host and Home Markets}

To measure the size of a host market, we use population and GDP of the host country obtained from World Development Indicators (WorldBank, 2011) and denote the variables population of host country and GDP of host country, respectively. The largest host country in terms of both GDP and population is Russia, while the smallest host countries are Estonia and Slovenia (in terms of population) and Tadjikistan and Moldavia (in terms of GDP). We define a dummy variable large host country to take a value of one if a host country has the same or larger population than the medium host country in our sample which is the Czech Republic with a population of 10.3 million. Since our parent firms are located either in Austria or Germany, we use a dummy variable parent is located in Germany to capture the effect of the larger home market. Alternatively, we calculate a relative measure of the host country market size with respect to the home market size as the population ratio (host/home) and GDP ratio (host/home), respectively.

\subsubsection{Measuring Market Competition}

We use several data sources to proxy for product market competition and the exposure to international trade. First, we obtain from our firm survey two subjective firmlevel measures of competition as perceived by parent and subsidiary firms. They are dummy variables indicating for each parent and subsidiary firm whether the firm faces many domestic competitors and many world competitors rather than few competitors, respectively. Second, we use the AMADEUS database from BureauVanDijk (2005) to calculate the sectoral Lerner index based on a large number of firms for the home and host countries of the multinational firm at the three-digit ISIC industry level. The 
Lerner index is defined as (1 - average profits/sales), where the average is taken, first, across all firms available in a three-digit industry in a specific country and, second, over the years 1996 to 2000 (see Tables 6 and 7 of the Data Appendix B for a more formal definition). Finally, we use sectoral trade data from the WITS UN COMTRADE and data on domestic production from the INDSTAT 4 (UNIDO, 2008) and STAN (OECD, 2009) databases to proxy for the exposure to international trade of the sector of parent and subsidiary firms. Based on these data, we calculate the import share (defined as total imports divided by domestic production) and the export share (defined as total exports divided by domestic production). The variables are calculated for each country at the three-digit industry level. If data at the three-digit industry level are missing, the two-digit level is used.

\subsection{Predictions and Empirical Results}

\subsubsection{Corporate Culture, Distance, and Technology}

We start by examining how the multinational firms' corporate culture, distance, and technology affect the decision to transplant their organisational form to other countries.

Prediction 1: Multinational firms with a more decentralised hierarchy and a stronger corporate culture (which makes a change of organisational form more costly) are more likely to transplant their business model to their subsidiary in the host country.

Prediction 2: The more costly is the communication between the multinational headquarters and the affiliate firm, the less likely it is that the multinational firm transplants its organisational form to its affiliate firm. The prediction holds, however, only when the host market is sufficiently large (when the affiliate firm is sufficiently large).

Prediction 3: A multinational firm transferring a more complex and innovative technology to its affiliate firm is more likely to transplant its organisational form to its affiliate firm.

These predictions were derived in Result 1, Result 5, and Result 6 of the previous section. 
To test Predictions 1 to 3, we consider the following econometric model of the probability of transplanting the organisational form to the affiliate firm in the host country.

$\operatorname{Prob}\left(\operatorname{trans}_{i j k}\right)=\partial_{1}+\partial_{2} d e c_{i j k}+\partial_{3} i n c_{i j k}+\partial_{4} d i s t_{i j k}+\partial_{5} d i s t_{i j k} * h o s t_{i j k}+\partial_{6}$ tech $_{i j k}+\partial_{7} w_{i j k}^{\prime}+\nu_{i j k}$

Here, trans $_{i j k}$ is a dummy variable taking the value 1 for a multinational firm which has fully transplanted its organisational form to its affiliate firm, i.e., when all corporate decisions except one have the same hierarchical rank in the affiliate firm as in the parent firm, and zero otherwise ${ }^{12} i$ denotes the firm, $j$ denotes the home country, and $k$ denotes the host country. $d e c_{i j k}$ indicates the level of decentralisation in the parent firm, i.e., the mean of a ranking between 1 (centralised) and 5 (decentralised) of corporate decisions depending on whether the CEO or the divisional manager in the firm take the decision. $i n c_{i j k}$ is a dummy variable indicating the cost of changing the organisational form. It is captured by whether the parent multinational firm has an explicit human resource policy in place. dist $_{i j k}$ measures the communication costs between parent and affiliate and is given by the geographic distance between the parent and affiliate firms. host $_{i j k}$ is a dummy variable with the value 1 when the host country is large and has a population above the host countries' median population, and zero otherwise. tech $_{i j k}$ indicates that the technology transferred to the affiliate firm is innovative rather than established or outdated. $w_{i j k}^{\prime}$ is a vector of controls and $\nu_{i j k}$ is an error term. In light of Predictions 1, 2, and 3, we test for the hypotheses $\partial_{2}>0$ and $\partial_{3}>0, \partial_{4}<0$ and $\partial_{5}<0$, and for $\partial_{6}>0$.

Our main findings are given in Table 2 which presents probit maximum likelihood estimates of equation 11. All p-values are computed allowing for heteroskedasticity at the firm level. Furthermore, all regressions include a set of industry dummies as well as host country fixed effects. We also include additional firm-level controls to avoid omitted variable bias. The additional firm level covariates are no intra-firm trade and the log of the number of employees in parent and affiliate firms as a measure of firm size. The size of the multinational corporation does not appear to influence the probability of transplanting their organisational form, while parent firms transplant significantly more often to affiliate firms when affiliate firms are a horizontal investment and do not

\footnotetext{
${ }^{12}$ See the results with several alternative measures of transplanting the mode of organisation in Table 8 of Appendix B.
} 
engage in intra-firm trade. Columns 1 to 3 test Prediction 1. The estimated coefficients on decentralisation in parent firm and on incentive salary parent firm are, as predicted by the theory, positive and highly significant at conventional levels, suggesting that more decentralised parent firms with larger costs of changing their organisational form tend to transplant their business model significantly more often. We measure human resources by whether or not multinational firms incentivise their workers by having performance based wages (column 2) or bonuses (column 3) in place. The latter two variables are two ways of measureing the corporate culture of a multinational firm. We assume that multinationals with explicit human resource policies have a stronger corporate culture and thus it will be more costly to change the organisation in the affiliate firm. To get a sense of the economic importance of each of the regressors, we report the marginal effects in the last column of Table 2. An increase in the level of decentralisation of the parent firm by one rank (an increase in hierarchical rank from 2 to 3 , for example) increases the probability of transplanting the organisational form by 11 percentage points, while multinational firms which use incentive wages to reward for performance are 39 percentage points more likely to transplant the organisational form.

Columns 4 and 6 test Prediction 2. The estimated coefficient on distance is already by itself negative and significant, suggesting that when the affiliate firm's distance to the parent firm doubles, the probability of transplanting decreases by 8 percentage points. When we interact distance with the large host market dummy, the negative effect becomes stronger, as predicted by the theory. The interaction of distance with the large subsidiary dummy, as an alternative of measuring the size of the host market, is however, not significant.

Finally, in columns 7 to 9 we test Prediction 3. The dummy variables technology is innovative or established rather than outdated are both positive and significant, suggesting that technology transfer and organisational transfer go hand in hand. The probability of transplanting increases most when the technology is innovative (when the technology is innovative rather than outdated the probability of transplanting increases by 32 percentage points (see the last column of Table 2). A similar picture emerges from the alternative measure of technology easy to copy. As predicted by the theory, the probability of transplanting declines when a competitor can easily copy the technology. 


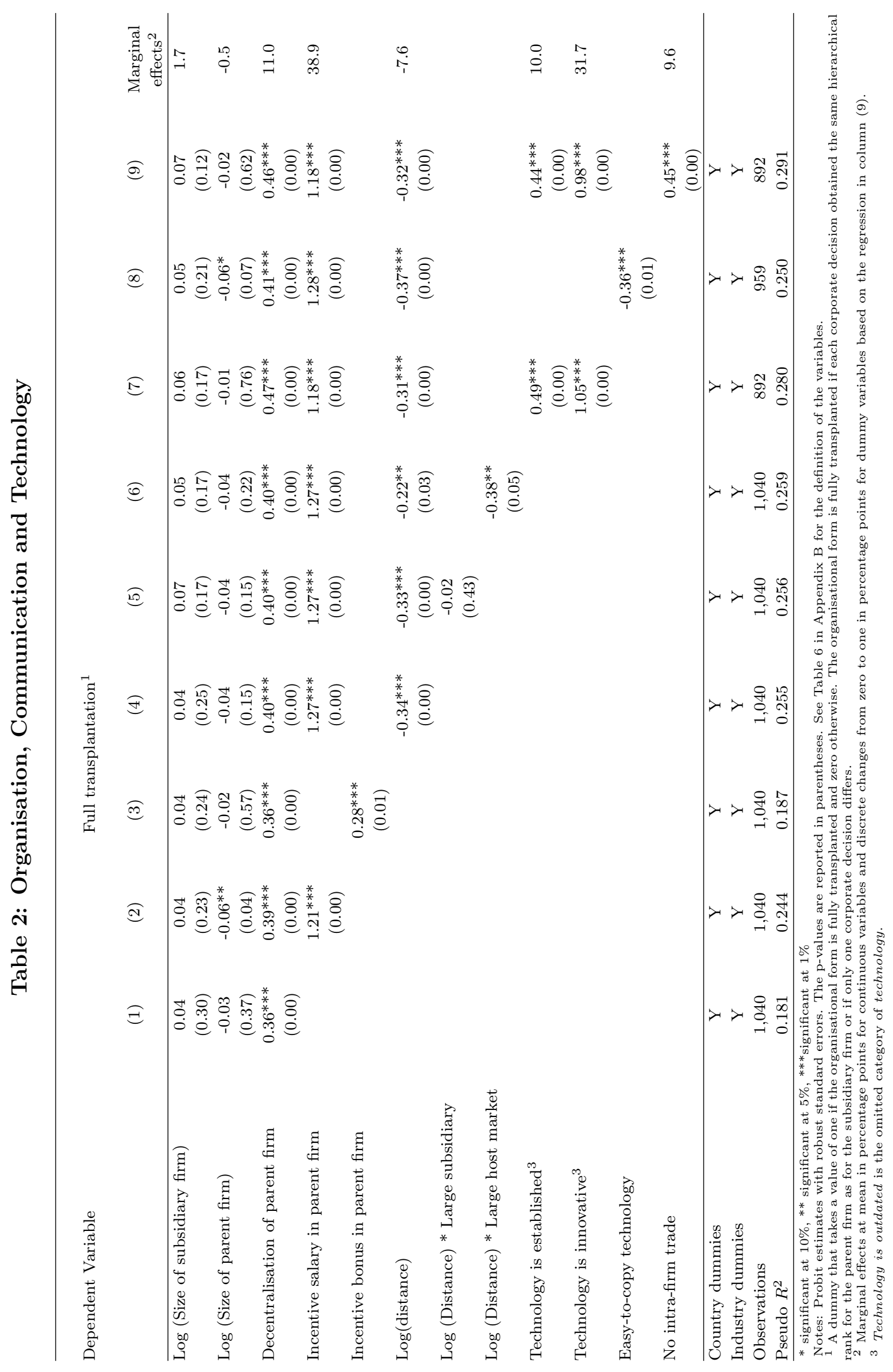




\subsubsection{Market Size}

Next, we study the relationship between the probability of transplanting the organisational form and the size of the market, which is summarised in Prediction 4.

Prediction 4: (a) A multinational firm is less likely to transplant its business model to an affiliate firm in a host country with a larger market size, (b) while it is more likely to transplant from a larger home market.

The prediction was derived in Results 2 and 3 of the theory section.

To test Prediction 4, we proceed with the following econometric specification.

$$
\operatorname{Prob}\left(\operatorname{trans}_{i j k}\right)=\theta_{1}+\theta_{2} \nabla_{i j k}^{\prime}+\theta_{3} \log \operatorname{pop}_{i j k}+\theta_{4} \text { germany }_{i j k}+\theta_{5} w_{i j k}^{\prime}+\epsilon_{i j k}
$$

Here, $\nabla_{i j k}^{\prime}$ is a vector of the organisational variables we have included to test Predictions 1-3 and pop is the size of the population in host countries as a measure of market size. The dummy germany takes a value of 1 if the home country is Germany and 0 when it is Austria. In light of Prediction 4, we test for $\theta_{3}<0$ and $\theta_{4}>0$.

Table 3 reports the findings of testing Prediction 4. Columns 2 and 3 examine how the size of the host country affects the probability of transplanting. As predicted by the theory, multinational firms are less likely to transplant their organisational form to host countries that arelarger in terms of either population or of GDP. The relationship is highly significant. Moreover, in column 4, the German dummy is positive and highly significant, suggesting that multinational firms originating from the larger home market are more likely to transplant their organisational form. Alternatively, in columns 5 and 6 we replace the absolute measure by a relative measure of market size by calculating the population ratio or GDP ratio of host to home country. The relationship is negative and highly significant, suggesting that if the population ratio increases by 1 , the probability of transplanting the organisational form declines by 2 percentage points (see the last column for the marginal effects). In our data this means that if a German multinational firm moves its affiliate from the Ukraine (with a population ratio of 0.6 ) to Russia (with a population ratio of 1.8 ), the probability of transplanting decreases by around 2.4 percentage points. Or alternatively, if an Austrian multinational firm moves its affiliate from Bulgaria (with a population ratio 
of 1) to Romania (with a population ratio of 2.8), the probability of transplanting declines by around 3.6 percentage points.

\subsubsection{Market Competition}

We proceed to examine how market competition and international trade influences a multinational firm's decision to tranplant its organisational form, which is summarised in the next prediction.

Prediction 5: (a) A multinational firm is more likely to transplant its business model to its affiliate firm facing tougher competition in its host market, (b) while it is less likely to transplant from a more competitive home market.

The prediction was derived in Result 4 of the theory section. To test Prediction 5 , we add several firm and sector specific proxies for competition and trade to the econometric specification 12. The results are given in Table 4. Columns 1 to 3 report results with the firm specific measures of competition and trade. As predicted by the theory, multinational firms transplant their business model significantly more often when they are faced with many foreign and domestic competitors in their host markets and they transplant their organisational form with lower probability when they are facing many foreign and domestic competitors in their home market. In column 2 many world competitors in the parent market becomes significant only, when we exclude the technology variables from the regression. Not surprisingly, the intensity of foreign competition affiliate firms face in their host markets is correlated with how innovative the technology is that they receive from their parent firms. Domestic competition in host and home markets of multinational firms is an important driver of organisational transfer to the host economies of Eastern Europe. When subsidiary firms face many domestic competitors in the host markets rather than few, the probability of transplanting increases by 18.5 percentage points, while many domestic competitors in the parent market lowers this probability by around 9 percentage points (see the last column of Table 4).

For robustness, we introduce several measures of competition at the sectoral level. In columns 4 and 5 we replace the firm-level measures of competition by the Lerner index at the sectoral 3-digit level. The results are robust with the subsidiary market Lerner but not for the parent market Lerner as the sign of the coefficient turns. 
Table 3: The Size of Host and Home Markets

Dependent Variable

(1)
$(2)$

(3)

$(4)$

(5)

(6) Marginal

Log (Size of subsidiary firm)

Log (Size of parent firm)

Decentralisation of parent firm

Incentive salary in parent firm

rentive salary in parent firm

Log (distance)

Technology is established ${ }^{3}$

Technology is innovative ${ }^{3}$

No intra-firm trade

Log (Population of host country)

$\log ($ GDP of host country)

Parent is located in Germany

Population ratio (host/home)

GDP ratio (host/home)

$\begin{array}{ccccccc}0.07 & 0.07 & 0.07 & 0.07 & 0.07 & 0.07 & 1.6 \\ (0.12) & (0.12) & (0.12) & (0.15) & (0.12) & (0.13) & \\ -0.02 & -0.02 & -0.02 & -0.04 & -0.02 & -0.03 & -0.5 \\ (0.62) & (0.62) & (0.62) & (0.36) & (0.55) & (0.45) & \\ 0.46^{* * *} & 0.46^{* * *} & 0.46^{* * *} & 0.49^{* * *} & 0.47^{* * *} & 0.47^{* * *} & 10.8 \\ (0.00) & (0.00) & (0.00) & (0.00) & (0.00) & (0.00) & \\ 1.18^{* * *} & 1.18^{* * *} & 1.18^{* * *} & 1.03^{* * *} & 1.13^{* * *} & 1.12^{* * *} & 36.6 \\ (0.00) & (0.00) & (0.00) & (0.00) & (0.00) & (0.00) & \\ -0.32^{* * *} & -0.32^{* * *} & -0.32^{* * *} & -0.54^{* * *} & -0.35^{* * *} & -0.39 * * * & -8.2 \\ (0.00) & (0.00) & (0.00) & (0.00) & (0.00) & (0.00) & \end{array}$

$\begin{array}{lllllll}0.44^{* * *} & 0.44^{* * *} & 0.44^{* * *} & 0.44^{* * *} & 0.44^{* * *} & 0.43^{* * *} & 9.7\end{array}$

$\begin{array}{llllll}(0.00) & (0.00) & (0.00) & (0.00) & (0.00) & (0.00)\end{array}$

$\begin{array}{llllll}0.98^{* * *} & 0.98^{* * *} & 0.98^{* * *} & 0.94^{* * *} & 0.98^{* * *} & 0.97^{* * *}\end{array}$

$\begin{array}{cccccc}(0.00) & (0.00) & (0.00) & (0.00) & (0.00) & (0.00) \\ 0.45^{* * *} & 0.45^{* * *} & 0.45^{* * *} & 0.43^{* * *} & 0.42^{* * *} & 0.42^{* * *} \\ (0.00) & (0.00) & (0.00) & (0.00) & (0.00) & (0.00)\end{array}$

Full transplantation ${ }^{1}$

\begin{tabular}{lcccccc}
\hline Country dummies & $\mathrm{Y}$ & $\mathrm{Y}$ & $\mathrm{Y}$ & $\mathrm{Y}$ & $\mathrm{Y}$ & $\mathrm{Y}$ \\
Industry dummies & $\mathrm{Y}$ & $\mathrm{Y}$ & $\mathrm{Y}$ & $\mathrm{Y}$ & $\mathrm{Y}$ & $\mathrm{Y}$ \\
Observations & 892 & 892 & 892 & 892 & 892 & 892 \\
Pseudo $R^{2}$ & 0.291 & 0.291 & 0.291 & 0.304 & 0.296 & 0.298
\end{tabular}

Notes: Probit estimates with robust standard errors. The p-values are reported in parentheses. See Table 6 in Appendix B for the

definition of the variables.
1 A dummy that takes a value of one if the organisational form is fully transplanted and zero otherwise. The organisational form is fully transplanted if each corporate decision obtained the same hierarchical rank for the parent firm as for the subsidiary firm or if only one corporate decision differs.

2 Marginal effects at mean in percentage points for continuous variables and discrete changes from zero to one in percentage points for dummy variables based on the regression in column (5).

3 Technology is outdated is the omitted category of technology. 
In column 5 we exclude the now insignificant population ratio which appears to be correlated with the Lerner index. However, parent market Lerner remains positive and significant when the population ratio is excluded. We proceed to include import and export ratios as sectoral measures of the exposure to international competition in columns 6 and 7. Now, the export share-parent has the expected negative sign and it is significant while import competition does not appear to be significant. However, the sample collapses to 260 observations, since the sectoral trade data were available only for a limited number of observations. We have the most confidence in the firm-level measures of competition, in light of the recent theory of heterogeneity and international trade, which suggests that firms vary in the amount of competition they face at the firm level 13

\section{Conclusion}

In this paper we investigate the conditions under which multinational firms transplant their business organisation to their affiliate firms in host countries. In concluding, we want to return to the puzzle we raised in the Introduction, that there is a surprisingly high proportion of multinational firms that do not transplant their mode of organisation to host countries. In our analysis we found that three factors stand out as drivers of organisational transfer to host countries. First, multinational firms with a strong corporate culture are 37 percentage points more likely to transplant their organisational form to host countries. A strong corporate culture makes it costly for multinational firms to change the organisational form and to choose a business model for affiliate firms which is optimally adjusted to the host market conditions. Among Austrian and German multinational firms in our data, however, only a minority (14 percent) face high costs of changing their organisational form by having human resource policies in place incentivising their workers (which is our proxy of corporate culture).

Second, multinational firms which transfer a new and highly innovative technology to affiliate firms in the host country are 31 percentage points more likely to export the business organisational form abroad. Our estimates suggest that technology transfer and organisational transfer go hand in hand. A new technology increases the

\footnotetext{
${ }^{13}$ see Melitz (2003).
} 
Table 4: Market Competition

Dependent Variable

(1)

(2)

(3)

Log (Size of subsidiary firm)

0.05

(0.27)

$\log$ (Size of parent firm)

Decentralisation of parent firm

$(0.27)$

$0.51 * * *$

(0.00)

Incentive salary in parent firm

$1.38^{* * *}$

$(0.00)$

Log (distance)

Technology is established ${ }^{3}$

$-0.40^{* * *}$

(0.00)

$0.50^{* * *}$

(0.00)

Technology is innovative ${ }^{3}$

$1.15^{* * *}$

(0.00)

No intra-firm trade

$0.44^{* * *}$

(0.01)

$-0.11^{* * *}$

(0.02)

Population ratio (host/home)

$-0.11^{* * *}$

(0.01)

Parent is located in Germany

Many world competitors-subs.

Many world competitors-par.

$-0.62^{* * *}$

(0.00)

$-0.41^{* * *}$

(0.00)

Many dom. competitors-subs.

Many dom. competitors-par.

Subsidiary market Lerner

Parent market Lerner

Import share-subsidiary

Import share-parent

Export share-subsidiary

$91^{* * *}$

(0.00)

$-0.45 * * *$

(0.01)

$\begin{array}{cc}0.05^{*} & 0.05^{*} \\ (0.05) & (0.08) \\ 0.09 * * * & 0.09 * * * \\ (0.00) & (0.00)\end{array}$

Full transplantation ${ }^{1}$
(4)
(5)

(6)

(7) Marginal effects $^{2}$

$\begin{array}{lllll}0.06 & 0.06 & 0.25^{* * *} & 0.24^{* *} & 1.7\end{array}$

$\begin{array}{llll}(0.19) & (0.20) & (0.01) & (0.01)\end{array}$

$\begin{array}{llll}0.03 & 0.01 & -0.22^{* *} & -0.22^{* *}\end{array}$

$\begin{array}{llll}(0.52) & (0.77) & (0.02) & (0.01)\end{array}$

$\begin{array}{llll}0.44^{* * *} & 0.45 * * * & 0.41 * * * & 0.41 * * *\end{array}$

$\begin{array}{llll}(0.00) & (0.00) & (0.00) & (0.00)\end{array}$

$1.21^{* * *} \quad 1.15^{* * *} \quad 2.06^{* * *} \quad 2.35^{* * *}$

$\begin{array}{llll}(0.00) & (0.00) & (0.00) & (0.00)\end{array}$

$-0.45^{* * *} \quad-0.54 * * *$

$-0.45^{* *}$

$-0.39^{* *}$

(0.03)

(0.00)

$0.33^{* *}$

(0.00)

(0.03)

$-0.02$

$-0.02$

(0.94)

(0.04) (0.03)

0.57

(0.28)

(0.00)

(0.00)

(0.31)

$0.76^{* * *}$

$0.63 * *$

(0.00)

(0.01)

(0.03)

$0.05 \quad 0.04$

(0.44) (0.50)

(0.76)

0.29

(0.16)

Export share-parent

Country dumas

Y Y

Y $\quad$ Y

Y

Industry dummies

Y $\quad \mathrm{Y}$

$\begin{array}{cc}\mathrm{Y} & \mathrm{Y} \\ \mathrm{Y} & \mathrm{Y}\end{array}$

$\mathrm{Y}$

Observations

852

964

Y

0.350

0.297

0.337

770

770

Y

$\mathrm{Y}$

Notes: Probit estimates with robust standard errors. The p-values are reported in parentheses. See Table 6 in Appendix $\mathrm{B}$ for the definition of the variables.

1 A dummy that takes a value of one if the organisational form is fully transplanted and zero otherwise. The organisational form is fully transplanted if each corporate decision obtained the same hierarchical rank for the parent firm as for the subsidiary firm or if only one corporate decision differs.

2 Marginal effects at mean in percentage points for continuous variables and discrete changes from zero to one in percentage points for dummy variables based on the regression in column (3).

3 Technology is outdated is the omitted category of technology. 
training costs of production managers in the affiliate firms, making a more centralised organisation in the affiliate firms more desirable. As the latter makes affiliate firms' organisational forms more similar to those in the parent firms (as parent firms are more centralised), this makes organisational transfer more likely. However, among the multinational firms in our sample, only very few (8 percent) describe the technology they transfer to host countries as new and highly innovative, while the majority of firms (60 percent) perceive the technology as established. Thus, the rare occurence of multinational firms with a strong corporate culture and with innovative technologies have both contributed to the low frequency of transplanting the mode of organisation to the affiliate firms in host countries.

Lastly, we find that multinational firms which invest in host countries with tough competition are 18.5 percentage points more likely to export their organisational form to these countries.

These findings suggest that organisational transfer between countries may be promoted by targeting multinational firms with strong corporate culture and innovative technologies. At the same time, host countries can influence the likelihood of such organisational transfer by creating a more competitive market environment in their countries once multinationals have decided to locate a subsidiary in these markets. This will be particularly desirable for large host countries which are at a disadvantage for obtaining organisational skills from their multinational investors. Whether, in fact, such policies are welfare improving to the host countries is beyond the scope of this paper.

\section{References}

Acemoglu, D., P. Aghion, C. Lelarge, J. V. Reenen, and F. Zilibotti. Technology, Information, and the Decentralization of the Firm. The Quarterly Journal of Economics, 122(4):1759-1799 (2007).

Antras, P., L. Garicano, and E. Rossi-Hansberg. Offshoring in a Knowledge Economy. The Quarterly Journal of Economics, 121(1):31-77 (2006).

Antras, P. and E. Helpman. Global Sourcing. Journal of Political Economy, 112(3):552580 (2004). 
Bloom, N., J. Van Reenen, and R. Sadun. Does Product Market Competition Lead Firms to Decentralize? American Economic Review, 100(2):434-38 (2010).

Bloom, N., J. Van Reenen, and R. Sadun. Americans Do IT Better: US Multinationals and the Productivity Miracle. American Economic Review, 102(1):167-201 (2012).

BureauVanDijk. AMADEUS database (2005). Available at http://www.bvdep.com/ en/Amadeus.html.

Caliendo, L., F. Monte, and E. Rossi-Hansberg. The Anatomy of French Production Hierarchies. NBER Working Papers 18259, National Bureau of Economic Research, Inc (2012).

Caliendo, L. and E. Rossi-Hansberg. The Impact of Trade on Organization and Productivity. The Quarterly Journal of Economics, 127(3):1393-1467 (2012).

Fernandez, R. Does Culture Matter? In Handbook of Social Economics, Vol. 1A, 481-510 (2011).

Fernandez, R. and A. Fogli. Culture: An Empirical Investigation of Beliefs, Work, and Fertility. American Economic Journal: Macroeconomics, 1(1):146-77 (2009).

Ferner, A., P. Almond, I. Clark, T. Colling, T. Edwards, L. Holden, and M. MullerCamen. Dynamics of Central Control and Subsidiary Autonomy in the Management of Human Resources: Case-study Evidence from US MNCs in the UK. Organization Studies, 25(3):363-391 (2004).

Fisman, R. and E. Miguel. Corruption, Norms, and Legal Enforcement: Evidence from Diplomatic Parking Tickets. Journal of Political Economy, 115(6):1020-1048 (2007).

Florida, R. and M. Kenney. Transplanted Organizations: The Transfer of Japanese Industrial Organization to the U.S. American Sociological Review, 56(3):381-398 (1991).

Garicano, L. Hierarchies and the Organization of Knowledge in Production. Journal of Political Economy, 108(5):874-904 (2000).

Garicano, L. and E. Rossi-Hansberg. Organization and Inequality in a Knowledge Economy. The Quarterly Journal of Economics, 121(4):1383-1435 (2006).

Guadalupe, M. and J. Wulf. The Flattening Firm and Product Market Competition: The Effect of Trade Liberalization on Corporate Hierarchies. American Economic Journal: Applied Economics, 2(4):105-27 (2010). 
Harrison, A. E. and A. Rodriguez-Clare. Trade, Foreign Investment, and Industrial Policy. In Handbook of Development Economics, Vol. 5, 4039-4214 (2010).

Helpman, E., D. Marin, and T. Verdier, eds. The Organization of Firms in a Global Economy. Harvard University Press (2008).

Helpman, E., M. J. Melitz, and S. R. Yeaple. Export versus FDI with Heterogeneous Firms. American Economic Review, 94(1):300-316 (2004).

Marin, D. The Theory of the Firm goes Global. CEPR Discussion Papers 8880 (2012).

Marin, D. and L. Rousova. The Organisation of European Multinationals. CEPR Discussion Papers 8881 (2012).

Marin, D. and T. Verdier. Power Inside the Firm and the Market: A General Equilibrium Approach. Journal of the European Economic Association, 6(4):752788 (2008).

Marin, D. and T. Verdier. Corporate Hierarchies and International Trade: Theory and Evidence. revised version (2010). http://www.iwb.vwl. uni-muenchen.de/forschung/veroffentlichungen/ver_-_marin/material/ powermarkup37-marin.pdf.

Marin, D. and T. Verdier. Globalization and the empowerment of talent. Journal of International Economics, 86(2):209-223 (2012).

Melitz, M. J. The Impact of Trade on Intra-Industry Reallocations and Aggregate Industry Productivity. Econometrica, 71(6):1695-1725 (2003).

OECD. Structural Analysis Database (STAN) (2009). Available at www.oecd.org/ sti/stan.

Ottaviano, G., T. Tabuchi, and J.-F. Thisse. Agglomeration and Trade Revisited. International Economic Review, 43(2):409-436 (2002).

Rajan, R. G. and J. Wulf. The Flattening Firm: Evidence from Panel Data on the Changing Nature of Corporate Hierarchies. The Review of Economics and Statistics, 88(4):759-773 (2006).

UNIDO. Industrial Statistics Database (INDSTAT 4, Revision 3) (2008). Available at http://www . unido.org/index.php?id=03533. 
WorldBank. World Integrated Trade Solution (WITS) (2009). Available at http: //wits.worldbank.org.

WorldBank. World Development Indicators (WDI) (2011). Available at http://data. worldbank.org/data-catalog/world-development-indicators.

\section{A Appendix: Theory}

- i) The first order conditions of the firm's problem are

$$
\begin{gathered}
R_{q}^{\prime}(q)-c\left(z_{p}, q\right)-c_{q}^{\prime}\left(z_{p}, q\right) q=0 \\
-c_{z}^{\prime}\left(z_{p}, q\right)=0 .
\end{gathered}
$$

Total differentiation gives

$$
\left[\begin{array}{cc}
R_{q q}^{\prime \prime}-2 c_{q}^{\prime}-c_{q q}^{\prime \prime} q & -c_{q z}^{\prime \prime} q \\
-c_{q z}^{\prime \prime} & -c_{z z}^{\prime \prime}
\end{array}\right]\left(\begin{array}{c}
d q^{*} \\
d z_{p}^{*}
\end{array}\right)=\left[\begin{array}{c}
-R_{q \alpha}^{\prime \prime} d \alpha+\left(c_{\beta}^{\prime}+c_{q \beta}^{\prime \prime} q\right) d \beta \\
c_{z \beta}^{\prime \prime} d \beta
\end{array}\right]
$$

or

$$
\left(\begin{array}{c}
d q^{*} \\
d z_{p}^{*}
\end{array}\right)=\frac{1}{\Delta}\left[\begin{array}{cc}
-c_{z z}^{\prime \prime} & c_{q z}^{\prime \prime} q \\
c_{q z}^{\prime \prime} & R_{q q}^{\prime \prime}-2 c_{q}^{\prime}-c_{q q}^{\prime \prime} q
\end{array}\right]\left[\begin{array}{c}
-R_{q \alpha}^{\prime \prime} d \alpha+\left(c_{\beta}^{\prime}+c_{q \beta}^{\prime \prime} q\right) d \beta \\
c_{z \beta}^{\prime \prime} d \beta .
\end{array}\right]
$$

The matrix

$$
A=\left[\begin{array}{cc}
R_{q q}^{\prime \prime}-2 c_{q}^{\prime}-c_{q q}^{\prime \prime} q & -c_{q z}^{\prime \prime} q \\
-c_{q z}^{\prime \prime} & -c_{z z}^{\prime \prime}
\end{array}\right]
$$

is semi-definite negative when $\Delta=-\left[R_{q q}^{\prime \prime}-2 c_{q}^{\prime}-c_{q q}^{\prime \prime} q\right] c_{z z}^{\prime \prime}-\left(c_{q z}^{\prime \prime}\right)^{2} q>0$ (which comes from the conditions ensuring a well defined maximization problem of the profit function $\pi(q, z))$. It follows immediately that

$$
\frac{\partial q^{*}}{\partial \alpha}=\frac{c_{z z}^{\prime \prime} R_{q \alpha}^{\prime}}{\Delta} ; \frac{\partial z_{p}^{*}}{\partial \alpha}=\frac{-c_{z q}^{\prime \prime} R_{q \alpha}^{\prime \prime}}{\Delta}
$$


and

$$
\begin{aligned}
\frac{\partial q^{*}}{\partial \beta} & =\frac{-c_{z z}^{\prime}\left[c_{\beta}^{\prime}+c_{q \beta}^{\prime} q\right]+c_{z \beta}^{\prime \prime} c_{z q}^{\prime} q}{\Delta} ; \\
\frac{\partial z_{p}^{*}}{\partial \beta} & =\frac{c_{z q}^{\prime \prime}\left[c_{\beta}^{\prime}+c_{q \beta}^{\prime} q\right]+c_{z \beta}^{\prime}\left[R_{q q}^{\prime}-2 c_{q}^{\prime}-c_{q q}^{\prime \prime} q\right]}{\Delta} .
\end{aligned}
$$

- Proof of Proposition 1: Assuming our parametrisation of the inverse demand function $P(q)$,

$$
P(q, \gamma, N, c, L)=\frac{2 \gamma}{2 \gamma+N}+\frac{N}{2 \gamma+N} c-\frac{\gamma}{L} q
$$

we obtain the revenue function of the firm:

$$
R(q)=P(q) q=\left[\frac{2 \gamma}{2 \gamma+N}+\frac{N}{2 \gamma+N} c-\frac{\gamma}{L} q\right] q
$$

which provides

$$
R^{\prime \prime}{ }_{q L}=2 \frac{\gamma}{L^{2}}>0 ; R^{\prime \prime}{ }_{q N}=\frac{2 \gamma(c-1)}{[N+2 \gamma]^{2}}<0
$$

Using (12), the result of Proposition 1 follows immediately QED.

- Proof of Proposition 2: Simple differentiation of the cost function

$$
c\left(z_{p}, q\right)=w_{p}+a_{p} z_{p}+h \frac{\left[1-F\left(z_{p}\right)\right]\left(a_{m}+w_{m}\right)}{1-\varphi q}
$$

provides the following expressions.

$$
\begin{gathered}
c_{a_{p}}^{\prime}=z_{p} ; \quad c_{h}^{\prime}=\frac{\left[1-F\left(z_{p}\right)\right]\left(a_{m}+w_{m}\right)}{1-\varphi q} ; \quad c_{z}=a_{p}-h f\left(z_{p}\right) \frac{a_{m}+w_{m}}{1-\varphi q} \\
c_{q}=h \frac{\varphi\left[1-F\left(z_{p}\right)\right]\left(a_{m}+w_{m}\right)}{[1-\varphi q]^{2}}
\end{gathered}
$$


Also,

$$
\begin{gathered}
c^{\prime \prime}{ }_{z a_{p}}=1, c^{\prime \prime}{ }_{z h}=-f\left(z_{p}\right) \frac{a_{m}+w_{m}}{1-\varphi q}<0 ; \\
c_{z z}=-h f^{\prime}\left(z_{p}\right) \frac{a_{m}+w_{m}}{1-\varphi q}>0 ; \\
c^{\prime \prime}{ }_{z q}=-h \frac{\varphi f\left(z_{p}\right)\left(a_{m}+w_{m}\right)}{[1-\varphi q]^{2}}<0, \quad c^{\prime \prime}{ }_{q a_{p}}=0 ; \\
c^{\prime \prime}=\frac{\varphi\left[1-F\left(z_{p}\right)\right]\left(a_{m}+w_{m}\right)}{[1-\varphi q]^{2}}>0 ; \\
c_{q q}^{\prime \prime}=2 h \frac{\varphi^{2}\left[1-F\left(z_{p}\right)\right]\left(a_{m}+w_{m}\right)}{[1-\varphi q]^{3}} .
\end{gathered}
$$

Now, using (13) and (16), one immediately gets

$$
\begin{aligned}
& \operatorname{Sign}\left(\frac{\partial q^{*}}{\partial a_{p}}\right)=\operatorname{Sign}\left[-c_{z z}^{\prime \prime} z_{p}+c_{z q}^{\prime \prime} q\right]<0 \\
& \operatorname{Sign}\left(\frac{\partial z_{p}^{*}}{\partial a_{p}}\right)=\operatorname{Sign}\left[c_{z q}^{\prime \prime} z_{p}+\left[R_{q q}^{\prime \prime}-2 c_{q}^{\prime}-c_{q q}^{\prime \prime} q\right]\right]<0 .
\end{aligned}
$$

Similarly, after substitution of (13), (16), and (17), one gets

$$
\begin{aligned}
& \operatorname{Sign}\left(\frac{\partial q^{*}}{\partial h}\right)=\operatorname{Sign}\left[-c_{z z}^{\prime \prime}\left[c_{h}^{\prime}+c_{q h}^{\prime} q\right]+c_{z h}^{\prime \prime} c_{z q}^{\prime} q\right] ; \\
& \operatorname{Sign}\left(\frac{\partial z_{p}^{*}}{\partial h}\right)=\operatorname{Sign}\left[c_{z q}^{\prime \prime}\left[c_{h}^{\prime}+c_{q h}^{\prime} q\right]+c_{z h}^{\prime \prime}\left[R_{q q}^{\prime \prime}-2 c_{q}^{\prime}-c_{q q}^{\prime \prime} q\right]\right] .
\end{aligned}
$$

Therefore,

$$
\begin{aligned}
\operatorname{Sign}\left(\frac{\partial q^{*}}{\partial h}\right) & =\operatorname{Sign}\left[h f^{\prime}\left(z_{p}\right)\left(a_{m}+w_{m}\right)^{2} \frac{\left[1-F\left(z_{p}\right)\right]}{[1-\varphi q]^{3}}+f\left(z_{p}\right)\left(a_{m}+w_{m}\right)^{2} h \frac{\varphi f\left(z_{p}\right)\left(a_{m}+w_{m}\right)}{[1-\varphi q]^{3}} q\right] \\
& =\operatorname{Sign}\left[f^{\prime}\left(z_{p}\right)\left[1-F\left(z_{p}\right)\right]+f^{2}\left(z_{p}\right) \varphi q\right] \gtrless 0 .
\end{aligned}
$$

As $\varphi q<1$, we have $\partial q^{*} / \partial h<0$ when $f^{\prime}\left(z_{p}\right)\left[\left[1-F\left(z_{p}\right)\right]\right]+f^{2}\left(z_{p}\right)<0$, which is true when the hazard rate function $f\left(z_{p}\right) /\left(1-F\left(z_{p}\right)\right)$ is decreasing at $z_{p}$. 
Conversely,

$$
\operatorname{Sign}\left(\frac{\partial z_{p}^{*}}{\partial h}\right)=\operatorname{Sign}\left[\begin{array}{c}
-h \frac{\varphi f\left(z_{p}\right)\left(a_{m}+w_{m}\right)}{[1-\varphi q]^{2}}\left[\frac{\left[1-F\left(z_{p}\right)\right]\left(a_{m}+w_{m}\right)}{[1-\varphi q]^{2}}\right] \\
-f\left(z_{p}\right) \frac{a_{m}+w_{m}}{1-\varphi q}\left[R_{q q}^{\prime \prime}-2 h \frac{\varphi\left[1-F\left(z_{p}\right)\right]\left(a_{m}+w_{m}\right)}{[1-\varphi q]^{2}}-c_{q q}^{\prime \prime} q\right]
\end{array}\right]
$$

and

$$
\begin{aligned}
\operatorname{Sign}\left(\frac{\partial z_{p}^{*}}{\partial h}\right) & =\operatorname{Sign}\left[\begin{array}{c}
-f\left(z_{p}\right) \frac{a_{m}+w_{m}}{1-\varphi q} R_{q q}^{\prime \prime}+f\left(z_{p}\right) \frac{a_{m}+w_{m}}{1-\varphi q} c_{q q}^{\prime \prime} q \\
+h \frac{\varphi f\left(z_{p}\right)\left[1-F\left(z_{p}\right)\right]\left(a_{m}+w_{m}\right)^{2}}{[1-\varphi q]^{3}}\left[\frac{1-2 \varphi q}{1-\varphi q}\right]
\end{array}\right] \\
& =\operatorname{Sign}\left[-f\left(z_{p}\right) \frac{a_{m}+w_{m}}{1-\varphi q} R_{q q}^{\prime \prime}+h \frac{\varphi f\left(z_{p}\right)\left[1-F\left(z_{p}\right)\right]\left(a_{m}+w_{m}\right)^{2}}{[1-\varphi q]^{4}}\right]>0 .
\end{aligned}
$$

\section{QED.}

\section{- Results 2 and 4a:}

The impact of the host market parameter $\alpha^{f}$ on the probability of transplanting the organisational form is given by the sign of $R_{\alpha q}^{\prime \prime}\left(q, \alpha^{f}\right)$. More specifically, when $R_{\alpha q}^{\prime \prime}\left(q, \alpha^{f}\right)>0$, an increase in $\alpha^{f}$ leads to less transplanting to the affiliate firm. Given our parametrisation of product market monopolistic competition in the affiliate country, we get that

$$
R_{q L^{f}}=2 \frac{\gamma^{f}}{\left(L^{f}\right)^{2}}>0 ; \quad{ }^{\prime \prime}{ }_{q N^{f}}=\frac{2 \gamma^{f}\left(c^{f}-1\right)}{\left[N^{f}+2 \gamma^{f}\right]^{2}}<0,
$$

from which the conclusions for Results 2 and 3 follow immediately. QED.

\section{- Result 3 and $4 \mathrm{~b}$ :}

From Proposition 1 we know that a multinational firm with a larger home market size $L$ is more likely to be decentralised and has a larger value of $z_{p}^{O}$. Assuming that $z_{p}^{f^{*}}>z_{p}^{O}$, this tends to reduce the organisational gap $z_{p}^{f^{*}}-z_{p}^{O}$ between the optimal organisational structure of the affiliate and that of the parent firm, making organisational transfer more likely.

Conversely, from Proposition 1, a multinational firm facing a larger number of competitors in its home market is more centralised with a smaller value of $z_{p}^{O}$. As this 
increases the organisational gap $z_{p}^{f^{*}}-z_{p}^{O}$, which makes local adjustment more beneficial to the affiliate, the likelihood of transplantation is thus reduced.

For the decision to transplant their organisational form (comparative statics on cost side parameters): an increase in $\beta^{f}$ increases the likelihood of organisational transfer when

$$
\left[c_{\beta}+c_{\beta q}^{\prime} q\right] \widetilde{q}^{\prime}(z)+c_{\beta z}^{\prime} \widetilde{q}(z)>0
$$

or

$$
\left[c_{\beta}+c_{\beta q}^{\prime \prime} q\right]\left[c_{z}^{\prime}+c_{z q}^{\prime \prime} q\right]+\left[R_{q q}^{\prime \prime}-2 c_{q}^{\prime}-c_{q q}^{\prime \prime} q\right] c_{\beta z}^{\prime \prime} q<0
$$

- Result 5: Consider a change in the communication cost $h^{f}$. Given (16), and (17), we have that

$$
\left[c_{h}^{\prime}+c_{h q}^{\prime \prime} q\right]\left[c_{z}^{\prime}+c_{z q}^{\prime} q\right]+\left[R_{q q}^{\prime \prime}-2 c_{q}^{\prime}-c_{q q}^{\prime \prime} q\right] c_{h z}^{\prime} q
$$

is given by

$$
\frac{\left[1-F\left(z_{p}\right)\right]\left(a_{m}+w_{m}\right)}{[1-\varphi q]^{2}} a_{p}-R_{q q}^{\prime \prime} f\left(z_{p}\right) \frac{a_{m}+w_{m}}{1-\varphi q} q+\frac{h f\left(z_{p}\right)\left[1-F\left(z_{p}\right)\right]\left(a_{m}+w_{m}\right)^{2}}{[1-\varphi q]^{4}}[2 \varphi q-1] .
$$

The first two terms are positive and the last one is also positive when $\varphi q>1 / 2$. Hence, when the host market size $L^{f}$ is large enough to ensure that $\varphi q^{f}>1 / 2$, we get that the sign of $(19)$ is positive and the sign of $(18)$ is negative. Consequently, an increase in communication costs between the parent and the affiliate firm reduces the likelihood of organisational transfer. ${ }^{14}$

\section{- Result 6:}

${ }^{14}$ Note that the condition on the host market size is sufficient but not necessary. Indeed, even for values $q<1 / 2 \varphi$, but such that

$$
\varphi q>\frac{1}{2}-\frac{[1-\varphi q]^{2}}{2} \frac{a_{p}}{h f(0)\left(a_{m}+w_{m}\right)},
$$

we have a positive sign for 19 , leading to the same result on the likelihood of transplanting. 
Given that $c_{a_{p}}^{\prime}=z_{p}, c{ }_{q a_{p}}=0$ and $c{ }_{z a_{p}}=1$, we have that

$$
\left[c_{a_{p}}+c_{a_{p} q}^{\prime}\right] \widetilde{q}(z)+c_{a_{p} z}^{\prime} \widetilde{q}(z)=z_{p} \widetilde{q}^{\prime}(z)+\widetilde{q}(z)>0
$$

as $\widetilde{q}^{\prime}(z)>0$ on the range $\left[z_{0}, z_{i}\right]$. Hence a larger value of $a_{p}$ increases the likelihood of transplanting the organisational form to the subsidiary firm. QED. 


\section{B Appendix: Data and Results}

Figure 4: The Frequency of Transplanting Organisational Form

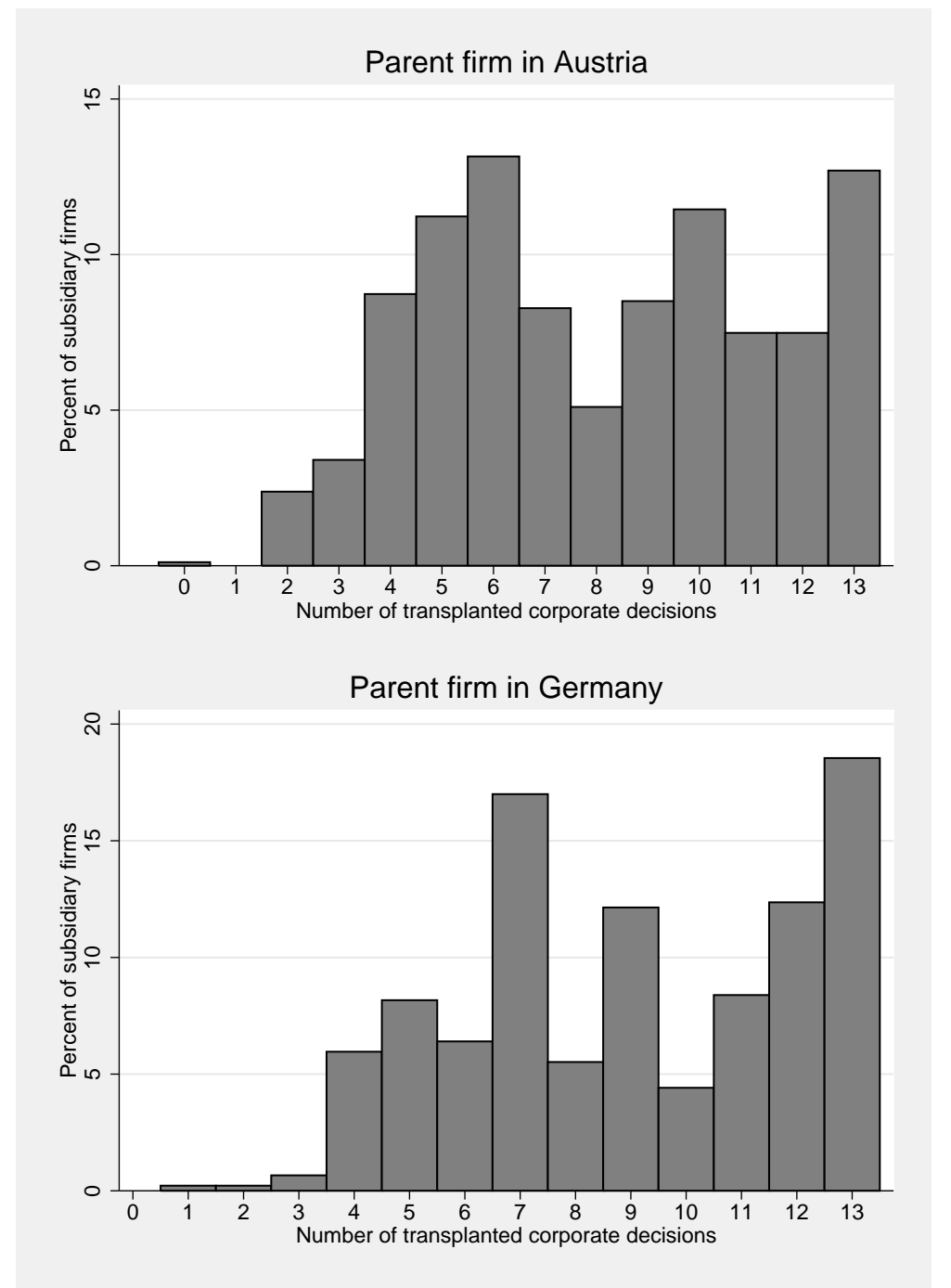

Notes: The organisational form is fully transplanted if each corporate decision obtained the same hierarchical rank for the subsidiary firm as for the parent firm or if only one corporate decision differs (i.e., 12 or 13 transplanted corporate decisions). It is partially transplanted if from two to four corporate decisions differ in hierarchical rank (i.e., 9-11 transplanted corporate decisions) and the organisational form is not transplanted if five or more corporate decisions are different (i.e., $0-8$ transplanted corporate decisions). 
Table 5: Corporate Decisions in Subsidiary and Parent Firms

Corporate decision $^{1} \quad$ Affiliates with the same $\quad$ Mean level of decentralisation ${ }^{3}$

hierarchical rank as parent firms ${ }^{2} \quad$ Affiliate firms $\quad$ Parent firms

\begin{tabular}{|c|c|c|c|}
\hline on acquisitions & $78 \%$ & 1.41 & 1.34 \\
\hline to hire a new secretary & $70 \%$ & 4.65 & 4.15 \\
\hline to hire two new workers & $64 \%$ & 4.26 & 3.67 \\
\hline to change a supplier & $61 \%$ & 3.23 & 3.09 \\
\hline on transfer prices & $61 \%$ & 2.43 & 2.45 \\
\hline on budget & $60 \%$ & 2.72 & 2.70 \\
\hline to hire 20 new workers & $59 \%$ & 2.82 & 2.51 \\
\hline on wage increase & $55 \%$ & 4.10 & 3.45 \\
\hline on product price & $54 \%$ & 3.75 & 3.48 \\
\hline on a new strategy & $54 \%$ & 1.88 & 1.90 \\
\hline financial decisions & $52 \%$ & 2.54 & 1.90 \\
\hline on $R \& D$ expenditure & $51 \%$ & 2.58 & 2.79 \\
\hline
\end{tabular}


Table 6: Description of Variables and Data Sources

Variable

Description

\section{Organisation, Communication, and Technology}

\section{Corporate Culture}

Full transplantation

Full transplantation (broad measure)

Decentralisation

of parent firm

Decentralisation of subsidiary firm

Incentive salary

in parent firm

Incentive bonus

in parent firm

\section{Communication costs}

Distance

\section{Technology}

Technology

$\hookrightarrow$ Technology is outdated

$\hookrightarrow$ Technology is established dummy that takes a value of one if the organisational form is fully transplanted from the parent firm to its subsidiary and zero otherwise; full transplantation means that either each corporate decision obtained the same hierarchical rank for the parent firm as for the subsidiary firm or only one corporate decision differs

dummy that takes a value of one if the organisational form is fully transplanted (in the broad sense) from the parent firm to its subsidiary and zero otherwise; full transplantation in the broad sense means that either each corporate decision obtained the same hierarchical rank for the parent firm as for the subsidiary firm or the rank differs for up to two corporate decisions

mean of ranking between one (centralised) and five (decentralised) of several corporate decisions depending on whether the headquarters (centralised) or the divisional manager of the parent firm (decentralised) makes the decision; see Table 5 for a listing of corporate decisions

mean of ranking between one (centralised) and five (decentralised) of several corporate decisions depending on whether the headquarters of the parent firm (centralised) or the subsidiary manager (decentralised) makes the decision; see Table 5 for a listing of corporate decisions

dummy that takes a value of one if the parent firm incentivises performance through salary increases and zero otherwise

dummy that takes a value of one if the parent firm incentivises performance though a one-off bonus payment and zero otherwise

distance between the parent and the subsidiary firm in $\mathrm{km}$

a categorical variable with three categories: technology is outdated, established, and new; a more detailed description of the categories follows

dummy that takes a value of one if the technology of the investment project is fully established or outdated and zero otherwise

dummy that takes a value of one if the technology of the investment project is relatively established and zero otherwise 


\begin{tabular}{ll} 
Variable & Description \\
\hline$\hookrightarrow$ Technology is innovative & $\begin{array}{l}\text { dummy that takes a value of one if the technology of the investment project is } \\
\text { new and zero otherwise }\end{array}$ \\
Easy-to-copy technology & $\begin{array}{l}\text { dummy that takes a value of one if the technology of the investment project can } \\
\text { easily be copied and zero otherwise }\end{array}$ \\
No intra-firm trade & $\begin{array}{l}\text { dummy that takes a value of one if no intra-firm trade between the parent and } \\
\text { the subsidiary firm takes place and zero otherwise }\end{array}$
\end{tabular}

\section{The Size of the Multinational Corporation}

$\begin{array}{ll}\text { Size of parent firm } & \text { number of employees of parent firm } \\ \text { Size of subsidiary firm } & \text { number of employees of subsidiary firm }\end{array}$

\section{The Size of Home and Host Markets}

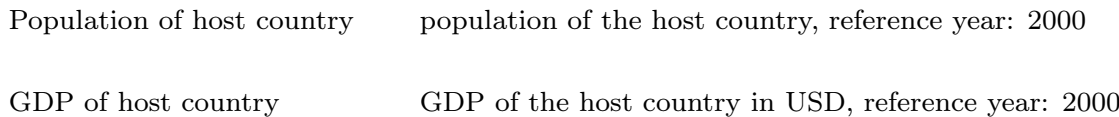

Large host country dummy that takes a value of one if population of the host market is equal to or larger than the medium observation in our sample of 10.3 million (the population of the Czech Republic) and zero otherwise

Parent is located dummy that takes a value of one if the parent firm is located in Germany and in Germany zero otherwise

Population ratio (host/home) ratio of host country population to home country population, reference year: 2000

GDP ratio (host/home) ratio of host country GDP to home country GDP, reference year: 2000

$\longrightarrow$ Source of population and GDP data: World Development Indicators $($ WorldBank, 2011)

\section{Market Competition}

Many domestic competitors

$\hookrightarrow$ subsidiary/parent

Many world competitors

$\hookrightarrow$ subsidiary/parent

Lerner

$\hookrightarrow$ subsidiary/parent market dummy that takes a value of one if the subsidiary/parent firm has many competitors at the domestic market and zero otherwise

dummy that takes a value of one if the subsidiary/parent firm has many competitors worldwide and zero otherwise

for a three-digit ISIC Rev. 3 industry $j$ of country $k$ :

$$
\text { Lerner }_{j k}=\left(1-\frac{1}{N_{j k}} \sum_{i \in j k} \frac{\text { profit before taxes }}{\text { operating revenue }} i\right) * 100 \% \text {, }
$$

where $N_{j k}$ denotes the number of firms $i$ in industry $j$ of country $k$; a simple 
average over the years 1996 to 2000 is taken in addition; parent market and subsidiary market Lerner denotes the Lerner index calculated for host countries and for Austria/Germany, respectively

$\longrightarrow$ Source of profit and revenue data: AMADEUS database (BureauVanDijk, 2005)

Import share total imports divided by domestic production at the three-digit ISIC Rev. 3 $\hookrightarrow$ subsidiary/parent market level in host/home countries and averaged over the years 1996 to 2000; when the three-digit level information is missing, the two-digit ISIC level is used

Export share total exports divided by domestic production at the three-digit ISIC Rev. 3 $\hookrightarrow$ subsidiary/parent market level in host/home countries and averaged over the years 1996 to 2000; when the three-digit level information is missing, the two-digit ISIC level is used

$\longrightarrow$ Source of trade data: WITS - UN COMTRADE database (WorldBank, 2009)

$\longrightarrow$ Source of production data: INDSTAT 4 (three-digit), STAN (two-digit) database (UNIDO, 2008; OECD, 2009)

$\longrightarrow$ Source of CEO wages: Kienbaum Consulting

\section{Other Variables}

Country dummies

Industry dummies $(2 \mathrm{~d})$ country dummies for the location of subsidiary firm

two-digit industry dummies for the subsidiary firm based on ISIC Rev. 3

Notes: If not reported otherwise, the data come from a survey of 660 German and Austrian firms with 2200 investment projects in Eastern Europe, conducted by the Chair of International Economics at the University of Munich. 
Table 7: Descriptive Statistics

\begin{tabular}{cccccc} 
Variable & Obs. Mean $\quad$ Min $\quad$ Max Std. Dev. $\begin{array}{c}\text { Obs. with } \\
\text { dummy }=1\end{array}$ \\
\hline
\end{tabular}

\section{Organisation, Communication, and Technology}

\section{Corporate Culture}

Full transplantation

Full transplantation (broad measure)

Decentralisation of parent firm

Decentralisation of subsidiary firm

Incentive salary in parent firm

Incentive bonus in parent firm

\section{Communication Costs}

Distance

\section{Technology}

Technology is outdated

Technology is established

Technology is innovative

Easy-to-copy technology

No intra-firm trade

$\begin{array}{ll}1335 & 0.24 \\ 1335 & 0.32 \\ 1472 & 2.81 \\ 1388 & 2.95 \\ 1549 & 0.14 \\ 1549 & 0.38\end{array}$

2122

903.04

17

6000

0.43

0.47

0.84

0.69

0.34

0.48

799.24

1826

1826

1826

1931

2123

0.32
0.60
0.08
0.35
0.67

0.32

0.60

0.08

0.67

1993

1921

6970.20

346.61

2122

2122

0.56

2123

2122

2122

24.9
78.4
0
0.56
1.18
0.17

1.37

0.86

1

0

0.2

0.0005

233000

49000

25233.78

1660.02

0.47

0.49

0.27

0.48

0.47

318

422

.

210

584

0.17

1978

2058

0.46

0.46

0.45

$\hookrightarrow$ Austria

936

$\hookrightarrow$ Germany

1122

0.46

1938

2010

Many world competitors-parent

0.29

0.73

$\hookrightarrow$ Austria

934

1076

0.72

$\hookrightarrow$ Germany

Subsidiary market Lerner

1900

Parent market Lerner

$\hookrightarrow$ Austria

$\hookrightarrow$ Germany

2053

0.73

96.57

93.68

92.83

$\begin{array}{cc}890 & 92.83 \\ 1163 & 94.32\end{array}$

$827 \quad 0.67$

$1053 \quad 0.38$

$327 \quad 0.58$

$\begin{array}{ll}726 & 0.30\end{array}$

$843 \quad 0.53$

$1053 \quad 0.40$

$\begin{array}{ll}327 & 0.47\end{array}$

726

0.37

$\begin{array}{cc}0 & 1 \\ 0 & 1 \\ 0 & 1 \\ 0 & 1 \\ 0 & 1 \\ 0 & 1 \\ 0 & 1 \\ 0 & 1 \\ 54.73 & 124.56 \\ 73.15 & 121.58 \\ 77.52 & 121.58 \\ 73.15 & 119.61 \\ 0.0028 & 23.74 \\ 0.012 & 1.89 \\ 0.03 & 1.52 \\ 0.01 & 1.89 \\ 0.0039 & 25.17 \\ 0.01 & 1.05 \\ 0.04 & 1.00 \\ 0.01 & 1.05\end{array}$

0.50

900

0.50

940

0.50

0.50

424

0.45

0.45

0.45

0.44

4.42

6.14

6.58

5.69

1.18

0.35

0.36

0.30

$\hookrightarrow$ Germany
Export share-subsidiary

Export share-parent

$\hookrightarrow$ Germany

0.01

1.07

0.26

0.30

0.24 


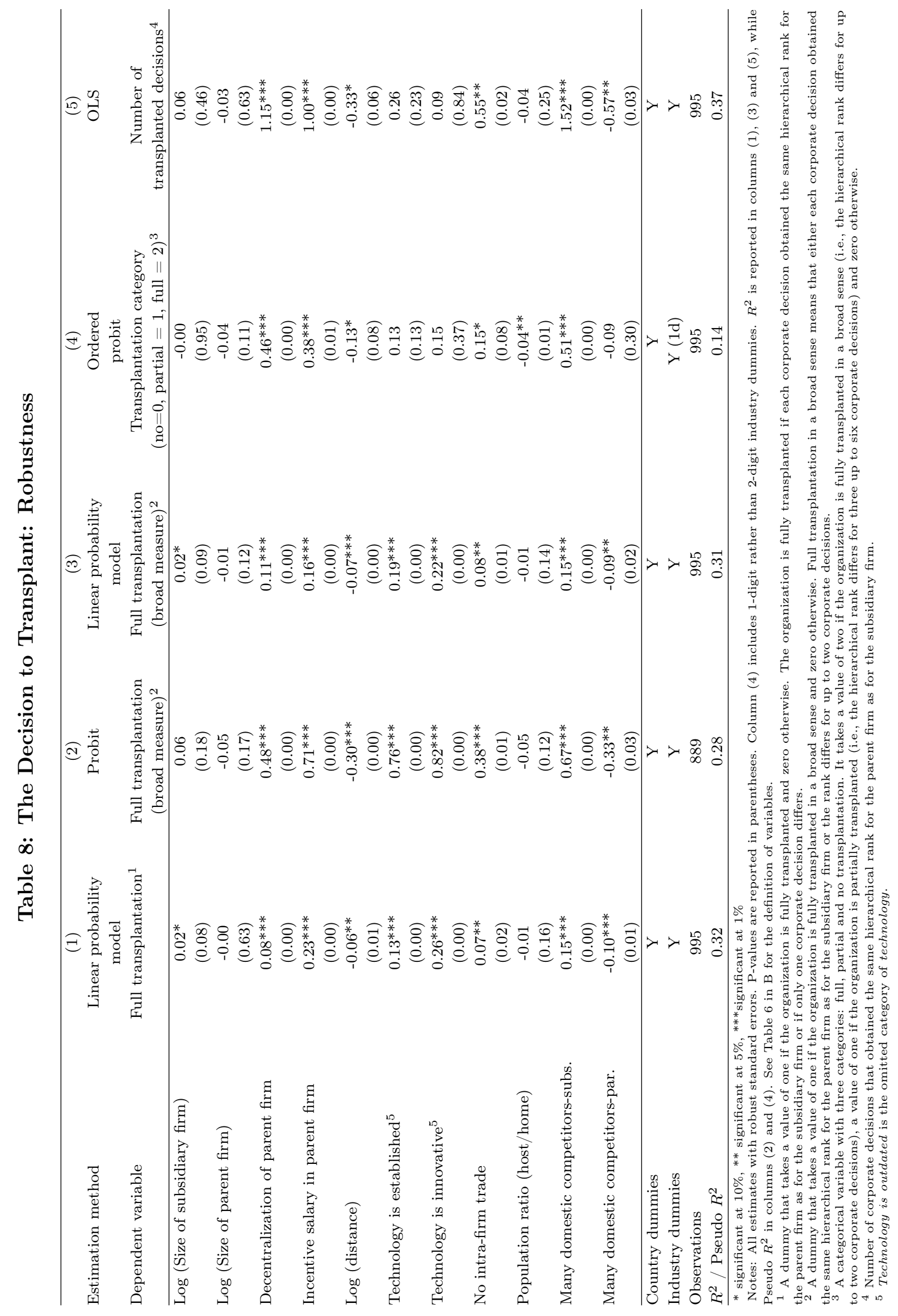

